\title{
Modeling of the anthropogenic heat flux and its effect on regional meteorology and air quality over the Yangtze River Delta region, China
}

\author{
Min Xie ${ }^{1}$, Jingbiao Liao ${ }^{1}$, Tijian Wang ${ }^{1,2}$, Kuanguang Zhu ${ }^{1}$, Bingliang Zhuang ${ }^{1}$, Yong Han ${ }^{1}$, Mengmeng Li ${ }^{1}$, and \\ Shu Li ${ }^{1}$ \\ ${ }^{1}$ School of Atmospheric Sciences, Nanjing University, Nanjing, China \\ ${ }^{2}$ CMA-NJU Joint Laboratory for Climate Prediction Studies, Institute for Climate and Global \\ Change Research, School of Atmospheric Sciences, Nanjing University, Nanjing, China
}

Correspondence to: Min Xie (minxie@ nju.edu.cn)

and Tijian Wang (tjwang@nju.edu.cn)

Received: 6 October 2015 - Published in Atmos. Chem. Phys. Discuss.: 18 November 2015

Revised: 22 April 2016 - Accepted: 3 May 2016 - Published: 18 May 2016

\begin{abstract}
Anthropogenic heat (AH) emissions from human activities caused by urbanization can affect the city environment. Based on the energy consumption and the gridded demographic data, the spatial distribution of AH emission over the Yangtze River Delta (YRD) region is estimated. Meanwhile, a new method for the AH parameterization is developed in the WRF/Chem model, which incorporates the gridded $\mathrm{AH}$ emission data with the seasonal and diurnal variations into the simulations. By running this upgraded WRF/Chem for 2 typical months in 2010, the impacts of AH on the meteorology and air quality over the YRD region are studied. The results show that the AH fluxes over the YRD have been growing in recent decades. In 2010, the annual-mean values of AH over Shanghai, Jiangsu and Zhejiang are $14.46,2.61$ and $1.63 \mathrm{~W} \mathrm{~m}^{-2}$, respectively, with the high value of $113.5 \mathrm{~W} \mathrm{~m}^{-2}$ occurring in the urban areas of Shanghai. These AH emissions can significantly change the urban heat island and urban-breeze circulations in the cities of the YRD region. In Shanghai, $2 \mathrm{~m}$ air temperature increases by $1.6^{\circ} \mathrm{C}$ in January and $1.4^{\circ} \mathrm{C}$ in July, the PBLH (planetary boundary layer height) rises up by $140 \mathrm{~m}$ in January and $160 \mathrm{~m}$ in July, and $10 \mathrm{~m}$ wind speed is enhanced by $0.7 \mathrm{~m} \mathrm{~s}^{-1}$ in January and $0.5 \mathrm{~m} \mathrm{~s}^{-1}$ in July, with a higher increment at night. The enhanced vertical movement can transport more moisture to higher levels, which causes the decrease in water vapor at ground level and the increase in the upper PBL (planetary boundary layer), and thereby induces
\end{abstract}

the accumulative precipitation to increase by $15-30 \%$ over the megacities in July. The adding of AH can impact the spatial and vertical distributions of the simulated pollutants as well. The concentrations of primary air pollutants decrease near the surface and increase at the upper levels, due mainly to the increases in PBLH, surface wind speed and upward air vertical movement. But surface $\mathrm{O}_{3}$ concentrations increase in the urban areas, with maximum changes of $2.5 \mathrm{ppb}$ in January and $4 \mathrm{ppb}$ in July. Chemical direct (the rising up of air temperature directly accelerates surface $\mathrm{O}_{3}$ formation) and indirect (the decrease in $\mathrm{NO}_{x}$ at the ground results in the increase in surface $\mathrm{O}_{3}$ ) effects can play a significant role in $\mathrm{O}_{3}$ changes over this region. The meteorology and air pollution predictions in and around large urban areas are highly sensitive to the anthropogenic heat inputs, suggesting that $\mathrm{AH}$ should be considered in the climate and air quality assessments.

\section{Introduction}

Nearly all energy used for human purposes can eventually turn into anthropogenic heat $(\mathrm{AH})$ within Earth's landatmosphere system (Flanner, 2009; Chen et al., 2012). According to the distinctive human activities all over the world, this heat flux might vary spatially and temporally. On the global scale, the averaged value of AH flux has been es- 
timated to be only $0.028 \mathrm{~W} \mathrm{~m}^{-2}$. But it can reach up to $0.39,0.68$ and $0.22 \mathrm{~W} \mathrm{~m}^{-2}$, respectively, over the continental United States, western Europe and China (Flanner, 2009). In the densely populated and economically vibrant urban areas, the $\mathrm{AH}$ fluxes have been reported to typically range from 20 to $70 \mathrm{~W} \mathrm{~m}^{-2}$ (Crutzen, 2004; Sailor and Lu, 2004; Fan and Sailor, 2005; Pigeon et al., 2007; Lee et al., 2009), whereas the fluxes might occasionally exceed the value of $100 \mathrm{~W} \mathrm{~m}^{-2}$ as well (Quah and Roth, 2012; Xie et al., 2015). Under some extreme conditions, the magnitude of $\mathrm{AH}$ fluxes in cities can be a substantial heat source equivalent to the daily mean solar forcing (Ichinose et al., 1999; Hamilton et al., 2009; Iamarino et al., 2012), with a high value of $1590 \mathrm{~W} \mathrm{~m}^{-2}$ reported in the densest part of Tokyo at the peak of air-conditioning demand (Ichinose et al., 1999). Consequently, accurate prediction of $\mathrm{AH}$ emissions is always a key issue that can improve our understanding of human impacts on urban climate and environment.

Anthropogenic heat can increase turbulent fluxes in sensible and latent heat, which might result in the atmosphere reserving more energy (Oke, 1988). Thus, the abovementioned heat fluxes exhausted from human activities in cities can exert a significant influence on the dynamics and thermodynamics of urban boundary layer (Ichinose et al., 1999; Block et al., 2004; Fan and Sailor, 2005; Chen et al., 2009, 2012; Bohnenstengel et al., 2014), and thereby change the surface meteorological conditions (Khan and Simpson, 2001; Block et al., 2004; Fan and Sailor, 2005; Ferguson and Woodbury, 2007; Chen et al., 2009; Zhu et al., 2010; Menberg et al., 2013; Wu and Yang, 2013; Feng et al., 2014; Bohnenstengel et al., 2014). Most previous studies of AH have focused on these effects. For instance, some researchers have found that AH strengthens the vertical movement of urban surface air flow, changes the urban heat island circulation, and makes the urban boundary layer more turbulent and unstable (Ichinose et al., 1999; Block et al., 2004; Fan and Sailor, 2005; Chen et al., 2009; Bohnenstengel et al., 2014). Others showed that $\mathrm{AH}$ in cities can result in significant and extensive warming, and tend to cause urban air temperatures to increase by several degrees (Fan and Sailor, 2005; Ferguson and Woodbury, 2007; Chen et al., 2009; Zhu et al., 2010; Menberg et al., 2013; Wu and Yang, 2013; Feng et al., 2014; Bohnenstengel et al., 2014). Moreover, Feng et al. (2014) reported that $\mathrm{AH}$ enhances the convergence of water vapor and rainfall amounts over urbanized areas, and changes the regional precipitation patterns to some extent. Urban air quality and local meteorological condition are inextricably linked. Therefore, all the findings above are likely to have important implications for air quality in urban areas as well. However, in the past, few researchers paid attention to this issue, and only a couple of studies have estimated the effects of AH on air pollutants (Ryu et al., 2013; Yu et al., 2014; Yang et al., 2014).

Over the past decades, along with the accelerated urbanization process and rapid economic development, many cities in China have been suffering the successive deterioration of air quality (Xie et al., 2014). Located in the coastal region in East China, the Yangtze River Delta (YRD) region also experienced a rapid urban expansion with the urbanization rate as high as $70 \%$ and suffered from air pollution (Liao et al., 2015). Consequently, several previous studies have tried to figure out the effects of urbanization on the severe atmospheric environmental problems in this region. For example, by using the WRF/Chem model, Wang et al. (2009) quantified that the urban sprawl in the YRD region has caused surface $\mathrm{O}_{3}$ to increase by $2.9-4.2 \%$ during the daytime and by $4.7-8.5 \%$ at night. Employing the WRF/CMAQ model, $\mathrm{Li}$ et al. (2011) showed that $\mathrm{O}_{3}$ and haze problems had become an important issue due to the increase in urban land use. Liao et al. (2015) further quantified the increase in $\mathrm{O}_{3}$ and the decrease in $\mathrm{PM}_{10}$ (or $\mathrm{NO}_{x}$ ) related to the urban expansion. Kang et al. (2014) discussed the impact of Shanghai urban land surface forcing on downstream city meteorology. Zhu et al. (2015) further studied this impact on $\mathrm{O}_{3}$ chemistry. However, the above studies only took the expansion of urban land use into account. We still need to know how the excessive anthropogenic heat from urban expansion impacts on urban climate and air quality. Among previous studies, a couple of researchers have tried to fill the knowledge gap. For instance, He et al. (2007) incorporated AH into a PBL (planetary boundary layer) model for Nanjing 2002 and found a temperature increase $\left(0.5-1^{\circ} \mathrm{C}\right)$ at night. Wang et al. (2015) reported that $\mathrm{AH}$ can cause notable warming in almost the whole YRD, which is more significant in winter than in summer. These studies only focused on the effects of AH on local meteorological fields. Till now, no studies have evaluated the influence of $\mathrm{AH}$ on air quality over the YRD region.

The main purpose of this study is to improve our understanding of the influence mechanism of anthropogenic heat on the atmospheric environment, especially in the typically polluted areas of China such as the YRD region. In this paper, we focus on (1) quantifying the spatial and temporal distribution of $\mathrm{AH}$ emissions in the YRD region, (2) implementing the gridded AH data in the modified WRF/Chem model with improved $\mathrm{AH}$ flux parameterization, and (3) evaluating the impacts of $\mathrm{AH}$ fluxes on meteorological conditions and air quality over the YRD region. Detailed descriptions about the estimating method for anthropogenic heat flux over the YRD region, the adopted air quality model with configuration, and the observation data for model evaluation are given in Sect. 2. The main results, including the spatial and temporal distribution of $\mathrm{AH}$, the performance of WRF/Chem, and the exact impacts of $\mathrm{AH}$ on urban climate and air quality are presented in Sect. 3. In the end, a summary is given in Sect. 4. 

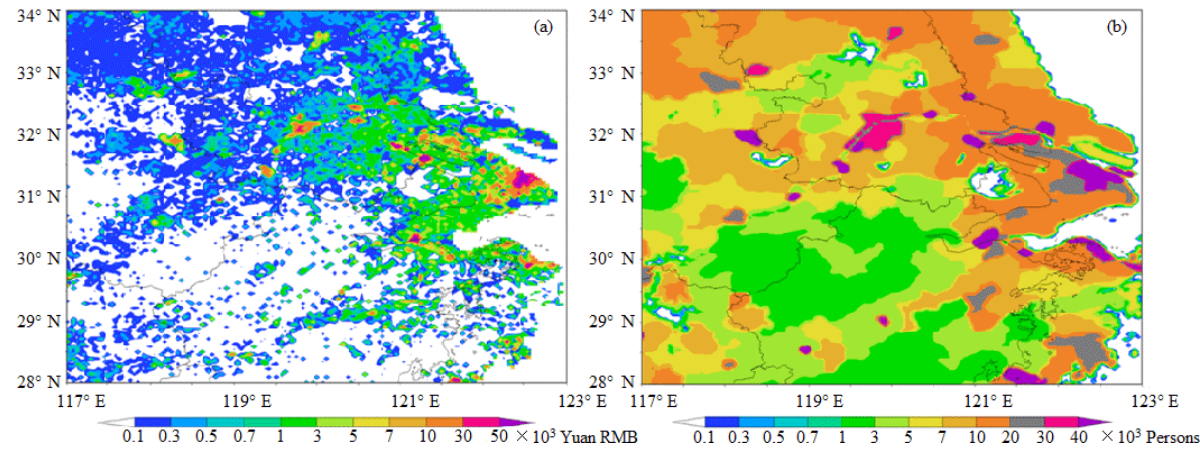

Figure 1. Spatial distribution of gross domestic product (a) and population (b) in 2010 over the region between $\left(117^{\circ} \mathrm{E}, 28^{\circ} \mathrm{N}\right)$ and $\left(123^{\circ} \mathrm{E}\right.$, $34^{\circ} \mathrm{N}$ ) with the resolution of $2.5 \mathrm{arcmin}$.

\section{Methodology}

\subsection{Anthropogenic heat flux modeling}

We estimate the $\mathrm{AH}$ fluxes during the period from 1990 to 2010 over the area between $\left(117^{\circ} \mathrm{E}, 28^{\circ} \mathrm{N}\right)$ and $\left(123^{\circ} \mathrm{E}\right.$, $34^{\circ} \mathrm{N}$ ), which covers the YRD region including Shanghai, southern Jiangsu province and northern Zhejiang province (shown in Fig. 1). In order to get the spatial distribution, this study area is also gridded as 144 rows and 144 columns with the grid spacing of 2.5 arcmin (approximately $4 \mathrm{~km}$ ).

The anthropogenic heat flux $Q_{\mathrm{F}}\left(\mathrm{W} \mathrm{m}^{-2}\right)$ is the rate at which waste energy is discharged by human activities to the surroundings (Iamarino et al., 2012). In urban areas, it usually consists of the heat flux derived from energy consumption in buildings $\left(Q_{\mathrm{F}, \mathrm{B}}\right)$, from the transportation sector $\left(Q_{\mathrm{F}, \mathrm{T}}\right)$ and from human metabolism $\left(Q_{\mathrm{F}, \mathrm{M}}\right)$ (Grimmond, 1992; Sailor and Lu, 2004; Allen et al., 2011; Iamarino et al., 2012; Quah and Roth, 2012). Three general approaches have been recognized to estimate these terms (Sailor, 2011), including the building energy modeling approach for the building sector (Kikegawa et al., 2003), the closure of the energy budget (Offerle et al., 2005), and the use of statistics on energy consumption (Sailor and Lu, 2004; Flanner, 2009; Hamilton et al., 2009; Lee et al., 2009; Allen et al., 2011; Iamarino et al., 2012; Quah and Roth, 2012). The third method, which is also called the top-down energy inventory method, was the most common approach and was widely applied in AH flux predictions in China (Chen et al., 2012; Lu et al., 2014; Xie et al., 2015). Based on these previous investigations, $Q_{\mathrm{F}}$ in this study is calculated by the following equation:

$Q_{\mathrm{F}}=Q_{\mathrm{F}, \mathrm{I}}+Q_{\mathrm{F}, \mathrm{B}}+Q_{\mathrm{F}, \mathrm{T}}+Q_{\mathrm{F}, \mathrm{M}}$,

where $Q_{\mathrm{F}, \mathrm{I}}$ represents the heat emitted from the industry sector $\left(\mathrm{W} \mathrm{m}^{-2}\right)$.

According to the second law of thermodynamics, most energy used for human economy is immediately dissipated as heat, other energy temporarily stored as electrical, mechanical, chemical or gravitational potential energy can finally transform to high entropy thermal energy as well, and only a negligible portion $(\ll 1 \%)$ might be converted to radiation and escape into space (Flanner, 2009). So, it is reasonable to assume that all non-renewable primary energy consumption is dissipated thermally in Earth's atmosphere. From another perspective, in this study, the gridded $\mathrm{AH}$ data are finally incorporated into the Single Layer Urban Canopy Model, SLUCM (Kusaka and Kimura, 2004; Chen et al., 2011), in which we do not need to strictly distinguish between different sources of $\mathrm{AH}$. As a result, $Q_{\mathrm{F}, \mathrm{I}}+Q_{\mathrm{F}, \mathrm{B}}+Q_{\mathrm{F}, \mathrm{T}}$ at each grid can be estimated on the basis of energy consumption from non-renewable sources (coal, petroleum, natural gas, and electricity) by using the following equation:

$Q_{\mathrm{F}, \mathrm{I}}+Q_{\mathrm{F}, \mathrm{B}}+Q_{\mathrm{F}, \mathrm{T}}=\eta \times \varepsilon_{\mathrm{S}} \times C_{\mathrm{s}} /(t \times A)$,

where $C_{\mathrm{S}}$ is the primary energy consumption that has been converted to standard coal $(t)$ at a grid. $\varepsilon_{\mathrm{S}}$ is the calorific value of standard coal (the conversion factor from primary energy consumption to heat), which is recommended to be $29271 \mathrm{~kJ} \mathrm{~kg}^{-1}$ in many previous studies (Chen et al., 2012; Lu et al., 2014; Xie et al., 2015). $\eta$ is the efficiency of heat release in different sectors, with the typical value of $60 \%$ for electricity or heat-supply sector and $100 \%$ for other sectors (Lu et al., 2014). $t$ is the time duration of used statistic data, and is set to be 365 (days in a year) $\times 24 \times 3600=31536000 \mathrm{~s}$ in this study. $A$ represents the area of a grid, which is about $4 \times 4 \mathrm{~km}^{2}$. To quantify the values of $C_{\mathrm{s}}$, the authoritative statistics of annual standard coal consumption from 1990 to 2010 at provincial level are firstly obtained from China Statistical Yearbooks and the yearbooks in Shanghai, Jiangsu and Zhejiang. Then, the total provincial energy consumption is apportioned to each grid according to population density and converted to annualmean gridded energy flux. The population density with the resolution of $2.5 \times 2.5 \mathrm{arcmin}$ in 1990, 1995, 2000, 2005 and 2010 can be downloaded from Columbia University's Socioeconomic Data and Applications Center. That for 2010 is shown in Fig. 1b for example. 


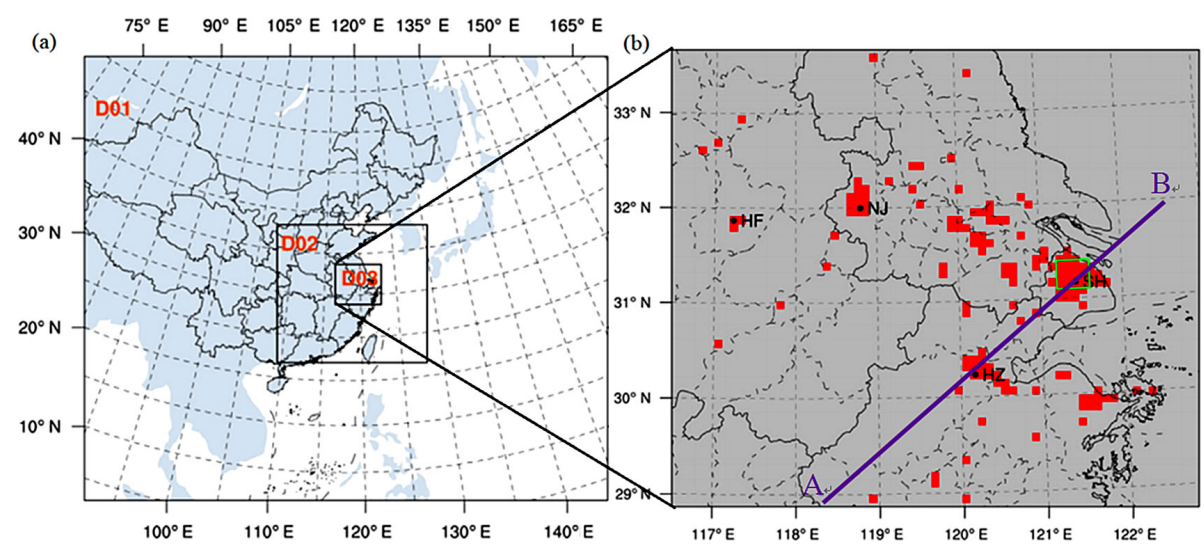

Figure 2. The three nested modeling domains (a) and MODIS urban land-use category data set used in D03, with the locations of the four meteorology observation sites (b). SH, HZ, NJ and HF in panel (b) represent Shanghai, Hangzhou, Nanjing and Hefei, respectively. Line AB denotes the location of the vertical cross section used in Figs. 9 and 12.

With respect to the heat flux generated by the human metabolism $\left(Q_{\mathrm{F}, \mathrm{M}}\right)$, the grid value is computed as

$Q_{\mathrm{F}, \mathrm{M}}=P_{\mathrm{g}} \times\left(M_{\mathrm{d}} \times 16+M_{\mathrm{n}} \times 8\right) / 24$,

where $P_{\mathrm{g}}$ is the population at a grid. $M_{\mathrm{d}}$ and $M_{\mathrm{n}}$ represent the average human metabolic rate $\left(\mathrm{W}\right.$ person $\left.{ }^{-1}\right)$ during the daytime and nighttime. The 16, 8 and 24 are the hours of daytime, nighttime and a whole day, respectively. Following the previous research work (Sailor and Lu, 2004; Chen et al., 2012; Lu et al., 2014; Xie et al., 2015), we assume that the sleeping metabolic rate $M_{\mathrm{n}}$ for a typical man is $75 \mathrm{~W}$, and the average daytime metabolic rate $M_{\mathrm{d}}$ in urban areas is $175 \mathrm{~W}$.

\subsection{Air quality model and configuration}

WRF/Chem version 3.5 is applied to investigate the impacts of AH fluxes on climate and air quality over the YRD region. WRF/Chem is a new generation of air quality modeling system developed at the National Center for Atmospheric Research (NCAR), in which the meteorological component (WRF) and the air quality component (Chem) are fully coupled using the same coordinates and physical parameterizations. The feedbacks between meteorology and air pollutants are included in the model. It has been proven to be a reliable tool in simulating air quality from city scale to meso scale in China (Liu et al., 2013; Yu et al., 2014; Liao et al., 2014, 2015).

As shown in Fig. 2a, three nested domains are used in this study, with the grid spacing of 81,27 and $9 \mathrm{~km}$, respectively. The outermost domain (Domain 1, D01) covers most of East Asia and South Asia, the second domain (Domain 2, D02) covers the central-eastern part of China, and the finest domain (Domain 3, D03) centered at Nanjing covers the entire YRD region (Fig. 2b). For all domains, from the ground level to the top pressure of $50 \mathrm{hPa}$, there are 36 vertical sigma layers, with about 10 in the PBL. The height of the lowest level is about $25 \mathrm{~m}$.
Two simulation cases are conducted. One incorporates the urban canopy model with the gridded AH fluxes that are estimated in Sect. 2.1 (referred to as the ADDAH case hereafter). The other only one applies the same model but ignores the contribution of AH (referred to as the NONAH case hereafter). To exclude the uncertainty conceivably caused by different configurations, all the physical schemes, chemical schemes and emission inventory are the same in both the NONAH and ADDAH simulations. Thus, the difference between the modeling results of NONAH and ADDAH can demonstrate the impacts of anthropogenic heat. In the YRD region, January and July can be representative of the dry and wet seasons, respectively (Liao et al., 2015). Consequently, two time periods are chosen for simulations and analysis. One is from 00:00 UTC 1 January to 00:00 UTC 1 February 2010, and the other is from 00:00 UTC 1 July to 00:00 UTC 1 August 2010, which also matches the time when observation data are available. The monthly averaged difference between ADDAH and NONAH can be calculated by the following algorithm:

$\mathrm{ADDAH}-\mathrm{NONAH}=\frac{\sum_{t=1}^{744}\left(V_{\mathrm{ADDAH}, t}-V_{\mathrm{NONAH}, t}\right)}{744}$,

where $V_{\mathrm{ADDAH}, t}$ and $V_{\mathrm{NONAH}, t}$ are the hourly modeling outputs of variable $V$ (meteorological factors or air pollutants) from ADDAH and NONAH, respectively. The monthly averaged differences of variables are calculated grid by grid. To guarantee the differences of one variable are statistically significant, a Student's $t$ test is carried out based on the data set from NONAH and ADDAH for each grid. At one grid, if the difference is non-significant under the $95 \%$ confidence level, we can assert that the AH flux cannot significantly change the meteorology or air quality at this grid (Zhuang et al., 2013a, b; Liao et al., 2015). 
Table 1. The grid settings, physics and chemistry options used in this study for WRF/Chem.

\begin{tabular}{ll}
\hline Items & Contents \\
\hline Dimensions $(x, y)$ & $(85,75),(76,70),(76,70)$ \\
Grid size $(\mathrm{km})$ & $81,27,9$ \\
Time step (s) & 360 \\
Microphysics & Purdue Lin microphysics scheme (Lin et al., 1983) \\
Longwave radiation & RRTM scheme (Mlawer et al., 1997) \\
Shortwave radiation & Goddard scheme (Kim and Wang, 2011) \\
Cumulus parameterization & Kain-Fritsch scheme, only for D01 and D02 (Kain, 2004) \\
Land surface & Noah land surface model (Chen and Dudhia, 2001) \\
Planetary boundary layer & Mellor-Yamada-Janjic scheme (Janjic, 1994) \\
Urban canopy model & SLUCM (Kusaka and Kimura, 2004) \\
Gas-phase chemistry & CBM-Z (Zaveri and Peters, 1999) \\
Aerosol module & MOSAIC using 8 sectional aerosol bins (Zaveri et al., 2008) \\
\hline
\end{tabular}

The detailed options for the physical and chemical parameterization schemes used in this study are shown in Table 1. The major selected physical options include the Purdue Lin microphysics scheme, the RRTM (Rapid Radiative Transfer Model) longwave radiation scheme, the Goddard shortwave radiation scheme, the Kain-Fritsch cumulus parameterization scheme, the Noah/LSM (Land Surface Model) scheme and the MYJ (Mellor-Yamada-Janjic) PBL scheme. Specifically, SLUCM (coupled with Noah/LSM) is adopted for better simulating the urban effect on meteorological conditions and pollutant distribution. The $30 \mathrm{~s}$ MODIS 20 category land data sets (Fig. 2b) are used to replace the default USGS (U.S. Geological Survey) land-use data, because USGS data are too outdated to illustrate the intensive land cover change over the YRD region. The default values for urban canopy parameters in SLUCM, such as building morphometry, urban fraction and roughness length, are replaced by the typical values in the YRD region as well, following the work of He et al. (2007) and Liao et al. (2015). The initial meteorological fields and boundary conditions (forced every $6 \mathrm{~h}$ ) are from NCEP global reanalysis data with $1^{\circ} \times 1^{\circ}$ resolution.

With respect to the major chemical options, the CBM$\mathrm{Z}$ gas-phase chemistry scheme and the MOSAIC aerosol scheme are chosen. CBM-Z (Carbon-Bond Mechanism version $\mathrm{Z}$ ) contains 55 prognostic species and 134 reactions ( $\mathrm{Za}-$ veri and Peters, 1999). In MOSAIC (Model for Simulating Aerosol Interactions and Chemistry), the aerosol size distribution is divided into eight discrete size bins (Zaveri et al., 2008). Besides aerosol direct and indirect effects through interaction with atmospheric radiation, photolysis, and microphysics, routines are also taken into account in our simulations. The modeling results from the MOZART-4 global chemistry transport model are used to provide the initial chemical state and boundary conditions as described by Liao et al. (2015). The anthropogenic emissions are mainly from the inventory developed for the NASA INTEX-B mission (Zhang et al., 2009), and modified for simulations in the YRD region (Liao et al., 2014, 2105). The ammonia emission and biomass burning emissions, which are not contained in the INTEX-B inventory, are obtained from the inventory developed for TRACE-P (Streets et al., 2003). For the Shanghai area, we use the additional $1 \mathrm{~km} \times 1 \mathrm{~km}$ source emission compiled by the Shanghai Environmental Monitoring Center during EXPO 2010 (Wang et al., 2012). The biogenic emissions are estimated by using MEGAN2.04 (Guenther et al., 2006).

\subsection{Methodology for incorporating gridded AH emission data}

Within the Single Layer Urban Canopy Model, SLUCM, the $\mathrm{AH}$ for each grid is determined by the fixed $\mathrm{AH}$ value for the urban land-use category, the fixed temporal diurnal pattern and the urban fraction value on each grid (Chen et al., 2011). AH with its diurnal variation is generally considered by adding them to the sensible heat flux from the urban canopy layer by the following equation:

$Q_{\mathrm{H}}=F_{V} \times Q_{\mathrm{H} V}+F_{U} \times\left(Q_{\mathrm{H} U}+\mathrm{Fix}_{\mathrm{AH}}\right)$,

where $Q_{\mathrm{H}}$ is the total sensible heat flux. $F_{V}$ and $F_{U}$ are the fractional coverage of natural and urban surfaces, respectively. $Q_{\mathrm{HV}}$ is the sensible heat flux from the Noah LSM for natural surfaces, and $Q_{\mathrm{HU}}$ is that from SLUCM for artificial surfaces. Fix ${ }_{\mathrm{AH}}$ represents the fixed $\mathrm{AH}$ value for all urban areas (Chen et al., 2011). In the ADDAH simulation case of this study, we basically follow Eq. (4) but incorporate the gridded $\mathrm{AH}$ data $\left(Q_{\mathrm{F}}\right)$ to replace the fixed $\mathrm{AH}$ value $\left(\mathrm{Fix}_{\mathrm{AH}}\right)$ in order to consider the spatial distribution of $\mathrm{AH}$ fluxes. The data estimated in Sect. 2.1 with the resolution of about $4 \mathrm{~km}$ are re-projected to Domain $3(9 \mathrm{~km})$ by the latitude and longitude of each grid. To account for temporal variability, the annual-mean $\mathrm{AH}$ fluxes in 2010 over the modeling area are further scaled with weighting functions dependent on local time of day $\left(t_{\mathrm{d}}\right)$ and time of year $\left(m_{\mathrm{y}}\right)$ :

$Q_{\mathrm{F}}\left(t_{\mathrm{d}}, m_{\mathrm{y}}\right)=Q_{\mathrm{F}} \times w_{\mathrm{d}}\left(t_{\mathrm{d}}\right) \times w_{\mathrm{y}}\left(m_{\mathrm{y}}\right)$, 


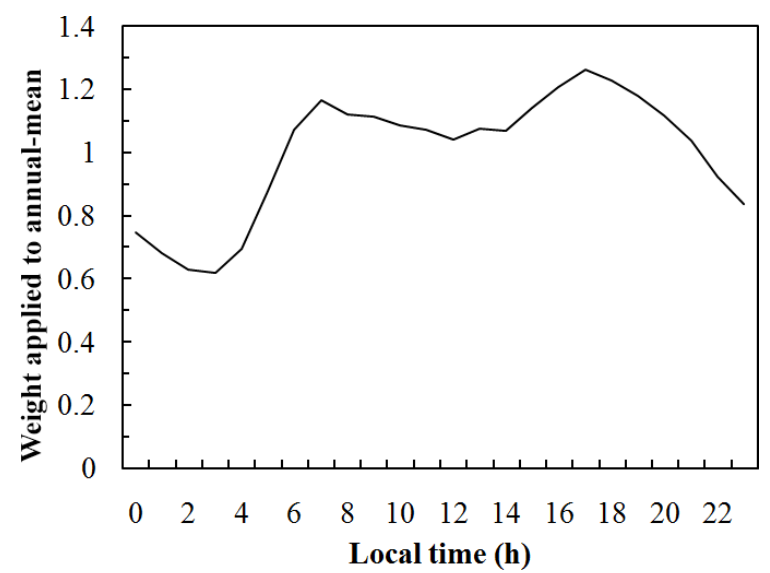

Figure 3. Diurnal variation of anthropogenic heat flux based on $\mathrm{He}$ et al. (2007), applied as weights to the annual-mean flux.

where the diurnal cycles of $w_{\mathrm{d}}$ are obtained from the work of He et al. (2007) for the YRD region (shown in Fig. 3). According to the findings of Sailor and Lu (2004) and Flanner (2009), the values of $w_{\mathrm{y}}$ for January and July are set to be 1.2 and 0.8 , respectively.

\subsection{Evaluation method and relevant observation data}

Meteorological and chemical observation records are used to evaluate the model performance in this study. The mean bias (MB), root mean square error (RMSE) and correlation coefficient (CORR) between observation and the ADDAH model results are used to verify model performance. In statistics, they are usually defined as

$$
\begin{aligned}
& \mathrm{MB}=\frac{1}{N} \sum_{i=1}^{N}\left(S_{i}-O_{i}\right), \\
& \mathrm{RMSE}=\sqrt{\frac{1}{N} \sum_{i=1}^{N}\left(S_{i}-O_{i}\right)^{2},} \\
& \mathrm{CORR}=\frac{\sum_{i=1}^{N}\left(S_{i}-S_{m}\right)\left(O_{i}-O_{m}\right)}{\sqrt{\sum_{i=1}^{N}\left(S_{i}-S_{m}\right)^{2}} \sqrt{\sum_{i=1}^{N}\left(O_{i}-O_{m}\right)^{2}}},
\end{aligned}
$$

where $S_{i}$ is the simulation and $O_{i}$ is the observation. $S_{m}$ and $O_{m}$ are the average values of simulations and observations, respectively. In general, the model performance is acceptable if the values of MB and RMSE are close to 0 and those of CORR are close to 1.

With respect to observed meteorological data, four observation sites are selected, which are $\mathrm{NJ}\left(32.00^{\circ} \mathrm{N}, 118.80^{\circ} \mathrm{E}\right)$ located in Nanjing, $\mathrm{HF}\left(31.87^{\circ} \mathrm{N}, 117.23^{\circ} \mathrm{E}\right)$ in Hefei, $\mathrm{HZ}\left(30.23^{\circ} \mathrm{N}, 120.16^{\circ} \mathrm{E}\right)$ in Hangzhou, and $\mathrm{SH}\left(31.40^{\circ} \mathrm{N}\right.$, $121.46^{\circ} \mathrm{E}$ ) in Shanghai, respectively (marked in Fig. 2b). Their time series of $2 \mathrm{~m}$ temperature, $10 \mathrm{~m}$ wind speed and
$2 \mathrm{~m}$ relative humidity in January and July of 2010 can be obtained from hourly records of the atmospheric sounding data set compiled by the University of Wyoming. In order to evaluate the model performance of chemical fields, hourly chemical series of $\mathrm{PM}_{10}$ and $\mathrm{O}_{3}$ during the modeling period are acquired from the Caochangmen (CCM) site. CCM is located in the central and highly residential area of Nanjing $\left(32.06^{\circ} \mathrm{N}, 118.74^{\circ} \mathrm{E}\right)$, and is run by the Nanjing Environmental Monitoring Center. The assurance/quality control (QA / QC) procedures at CCM strictly follow the national standards.

\section{Results and discussions}

\subsection{Spatial and temporal distribution of anthropogenic heat flux in the YRD region}

Using the methodology outlined above in Sect. 2.1, we construct the spatial distribution of anthropogenic heat fluxes over the YRD region from 1990 to 2010 with a 5-year interval. Figure 4 illustrates the gridded distribution in 1995, 2000, 2005 and 2010 (the magnitude and spatial distribution pattern in 1990 are similar to 1995). Obviously, big cities, such as Shanghai, Nanjing, and Hangzhou, have the largest values among neighboring areas from the early 1990s till now. Before 2000, except for some megacities, AH fluxes are generally less than $2.5 \mathrm{~W} \mathrm{~m}^{-2}$ in most parts of the YRD region. However, after 2000, the AH fluxes are more than $5 \mathrm{~W} \mathrm{~m}^{-2}$ in many areas, with the high values over $25 \mathrm{~W} \mathrm{~m}^{-2}$ centrally appearing along the Yangtze River, around Lake Taihu and beside Hangzhou Bay. The temporal variation of the spatial pattern fits in well with the economic boom in the YRD region over the past decades.

Being the largest city, Shanghai always has the highest anthropogenic heat emissions in the YRD region. As shown in Table 2, the annual-mean value over the whole administrative district is $5.47 \mathrm{~W} \mathrm{~m}^{-2}$ in 1990 and $14.45 \mathrm{~W} \mathrm{~m}^{-2}$ in 2010 , with the annual growth of $0.45 \mathrm{~W} \mathrm{~m}^{-2}$. In recent years, the AH fluxes in the city center of Shanghai have exceeded $100 \mathrm{~W} \mathrm{~m}^{-2}$, which is comparable to those in the most crowded megacities, such as Tokyo (Ichinose et al., 1999), Hong Kong (Flanner, 2009), London (Hamilton et al., 2009; Iamarino et al., 2012) and Singapore (Quah and Roth, 2012). The annual-mean values in the downtown area are much higher than the regional ones. With respect to Jiangsu province and Zhejiang province, the $\mathrm{AH}$ fluxes there also increase from 0.68 and $0.33 \mathrm{~W} \mathrm{~m}^{-2}$ in 1990 to 2.61 and $1.63 \mathrm{~W} \mathrm{~m}^{-2}$ in 2010 . The regional annual-mean values in Jiangsu higher than those in Zhejiang can be attributed to the fact that there are more large state-owned enterprises (including petrochemical companies and power plants) in Jiangsu. Furthermore, the AH fluxes in the urban areas of Jiangsu and Zhejiang range from 20 to $50 \mathrm{~W} \mathrm{~m}^{-2}$ in recent decades. These high values are close to those in Toulouse of France 

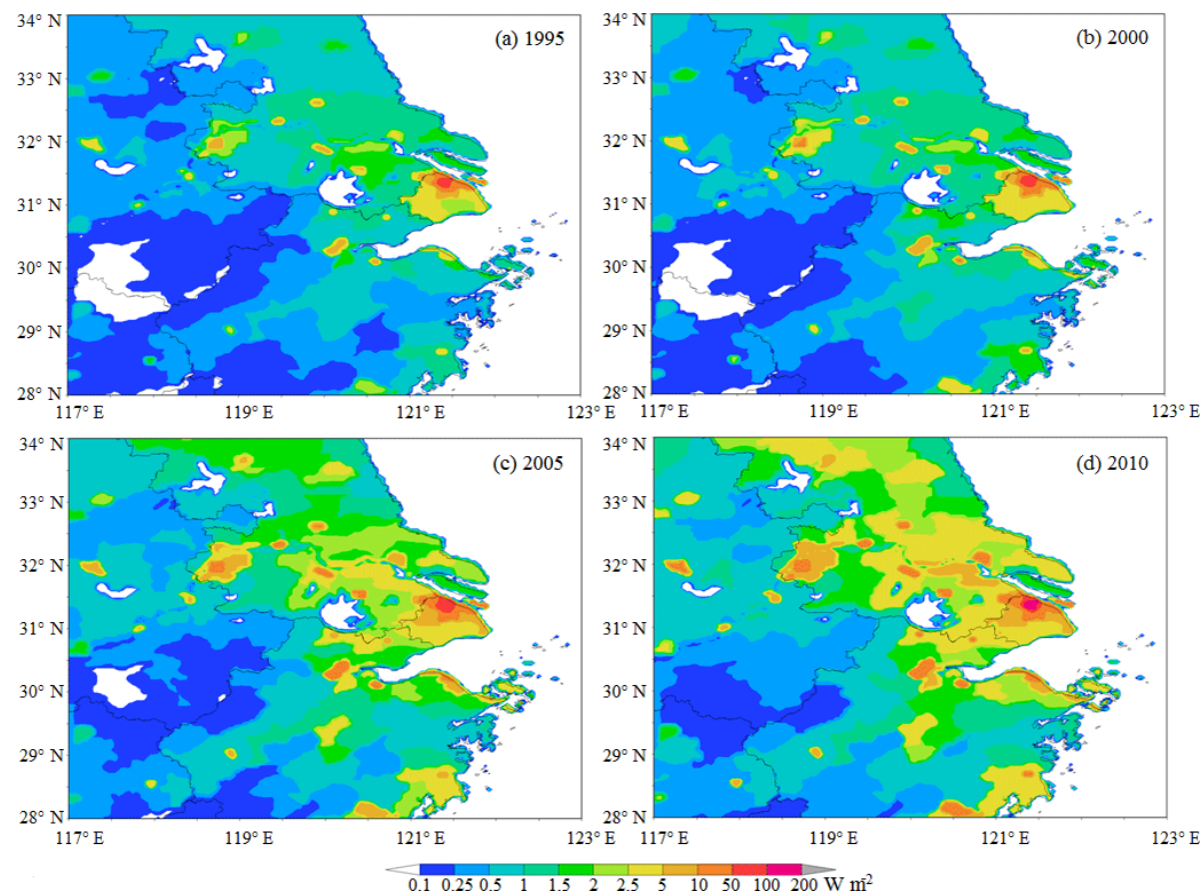

Figure 4. Estimates of annual-mean anthropogenic heat fluxes resulting from the consumption of non-renewable energy sources (coal, petroleum, natural gas, and electricity) and human metabolism between $\left(117^{\circ} \mathrm{E}, 28^{\circ} \mathrm{N}\right)$ and $\left(123^{\circ} \mathrm{E}, 34^{\circ} \mathrm{N}\right)$ with the resolution of 2.5 arcmin for 1995 (a), 2000 (b), 2005 (c) and 2010 (d), respectively.

Table 2. The statistics of annual average anthropogenic heat flux in different administrative districts over the $\mathrm{YRD}^{\mathrm{region}}\left(\mathrm{W} \mathrm{m}^{-2}\right)$.

\begin{tabular}{|c|c|c|c|c|c|c|c|c|}
\hline \multicolumn{2}{|c|}{ Province or municipality } & \multicolumn{5}{|c|}{ This study } & \multirow[t]{2}{*}{ Previous results (year) } & \multirow[t]{2}{*}{ References } \\
\hline & & 1990 & 1995 & 2000 & 2005 & 2010 & & \\
\hline \multirow[t]{3}{*}{ Shanghai } & Regional & 5.47 & 7.85 & 9.2 & 12.39 & 14.45 & $16.54(2008)$ & Chen et al. (2012) \\
\hline & & & & & & & $16.10(2010)$ & Lu et al. (2014) \\
\hline & Downtown & 42 & 60.8 & 71.6 & 96.9 & 113.5 & $117.7(2010)$ & Lu et al. (2014) \\
\hline \multirow[t]{3}{*}{ Jiangsu } & Regional & 0.68 & 0.94 & 0.99 & 1.83 & 2.61 & $2.32(2008)$ & Chen et al. (2012) \\
\hline & Downtown & 5.1 & 9.5 & 12.5 & 28.6 & 50.2 & 40 (Nanjing, 2007) & He et al. (2007) \\
\hline & & & & & & & $20-70(2010)$ & Lu et al. (2014) \\
\hline \multirow[t]{3}{*}{ Zhejiang } & Regional & 0.33 & 0.54 & 0.73 & 1.25 & 1.63 & $1.60(2008)$ & Chen et al. (2012) \\
\hline & Downtown & 2.7 & 7.4 & 12.1 & 25.1 & 39.3 & 50 (Hangzhou, 2007) & He et al. (2007) \\
\hline & & & & & & & $20-70(2010)$ & Lu et al. (2014) \\
\hline
\end{tabular}

Regional represents the average value over the whole area of an administrative district, while Downtown represents the high value in the city center.

(Pigeon et al., 2007), Seoul of Korea (Lee et al., 2009), and some large US cities (Sailor and Lu, 2004; Fan and Sailor, 2005).

In 2010, nearly all areas of the YRD region had AH fluxes of more than $2.5 \mathrm{~W} \mathrm{~m}^{-2}$ (shown in Fig. 4d). High fluxes generally occur in and around the cities, such as Shanghai, Nanjing, Hangzhou, Yangzhou, Zhenjiang, Taizhou, Changzhou, Wuxi, Suzhou, Nantong, Huzhou, Jiaxing, Shaoxing, and Ningbo, with typical values of $113.5,50.2$ and $39.3 \mathrm{~W} \mathrm{~m}^{-2}$ in the urban areas of Shanghai, Jiangsu and Zhejiang, respectively (shown in Table 2). Comparing Fig. 4d with Fig. 1, we can easily find that the spatial distribution of AH based on the population reflects the economic activities in the YRD region as well, suggesting that our method is effective and the results are reasonable. Moreover, as shown in Table 2, parts of our conclusion can be supported by some other previous studies (He et al., 2007; Chen et al., 2012; Lu et al., 2014; Xie et al., 2015). Therefore, the gridded AH fluxes can be used in meso-scale meteorological and environmental modeling to investigate their impacts on urban climate and air quality. 
Table 3. The statistics of meteorological conditions from the ADDAH simulation at four sites.

\begin{tabular}{|c|c|c|c|c|c|c|c|c|c|c|c|}
\hline \multirow[t]{3}{*}{$\operatorname{Vars}^{\mathrm{a}}$} & \multirow[t]{3}{*}{ Sites $^{b}$} & \multicolumn{5}{|c|}{ January } & \multicolumn{5}{|c|}{ July } \\
\hline & & \multicolumn{2}{|c|}{ Mean $^{c}$} & \multirow[t]{2}{*}{$\mathrm{MB}$} & \multirow[t]{2}{*}{ RMSE } & \multirow[t]{2}{*}{$\mathrm{CORR}^{\mathrm{d}}$} & \multicolumn{2}{|c|}{ Mean $^{c}$} & \multirow[t]{2}{*}{$\mathrm{MB}$} & \multirow[t]{2}{*}{ RMSE } & \multirow[t]{2}{*}{$\mathrm{CORR}^{\mathrm{C}}$} \\
\hline & & $\mathrm{OBS}^{\mathrm{e}}$ & $\operatorname{SIM}^{\mathrm{f}}$ & & & & $\mathrm{OBS}^{\mathrm{e}}$ & $\operatorname{SIM}^{\mathrm{f}}$ & & & \\
\hline \multirow[t]{4}{*}{$T_{2}\left({ }^{\circ} \mathrm{C}\right)$} & $\mathrm{NJ}$ & 3.5 & 5.1 & 1.6 & 2.2 & 0.92 & 28.2 & 30.2 & 2.0 & 2.0 & 0.83 \\
\hline & $\mathrm{HZ}$ & 5.7 & 7.4 & 1.7 & 1.9 & 0.93 & 28.7 & 30.5 & 1.8 & 2.2 & 0.80 \\
\hline & $\mathrm{HF}$ & 3.6 & 5.1 & 1.5 & 2.2 & 0.91 & 28.9 & 30.6 & 1.7 & 2.1 & 0.76 \\
\hline & $\mathrm{SH}$ & 5.6 & 6.7 & 1.1 & 1.6 & 0.94 & 28.8 & 29.5 & 0.7 & 1.7 & 0.85 \\
\hline \multirow[t]{4}{*}{$\mathrm{RH}_{2}(\%)$} & $\mathrm{NJ}$ & 65 & 53 & -12 & 14 & 0.74 & 76 & 68 & -9 & 10 & 0.71 \\
\hline & $\mathrm{HZ}$ & 67 & 60 & -7 & 10 & 0.83 & 74 & 70 & -4 & 17 & 0.71 \\
\hline & $\mathrm{HF}$ & 71 & 51 & -20 & 13 & 0.75 & 88 & 69 & -19 & 12 & 0.62 \\
\hline & $\mathrm{SH}$ & 70 & 64 & -6 & 11 & 0.79 & 76 & 72 & -4 & 11 & 0.77 \\
\hline \multirow[t]{4}{*}{$\mathrm{WS}_{10}\left(\mathrm{~m} \mathrm{~s}^{-1}\right)$} & $\mathrm{NJ}$ & 2.6 & 3.1 & 0.5 & 1.2 & 0.61 & 2.9 & 3.2 & 0.3 & 1.3 & 0.53 \\
\hline & $\mathrm{HZ}$ & 2.5 & 2.6 & 0.1 & 1.0 & 0.69 & 2.4 & 2.5 & 0.1 & 1.3 & 0.34 \\
\hline & $\mathrm{HF}$ & 2.6 & 2.9 & 0.3 & 1.1 & 0.67 & 2.3 & 2.7 & 0.4 & 1.2 & 0.40 \\
\hline & $\mathrm{SH}$ & 4.1 & 3.8 & -0.3 & 1.2 & 0.78 & 4.1 & 3.6 & -0.5 & 1.2 & 0.66 \\
\hline
\end{tabular}

${ }^{\text {a }}$ Vars represents the variables, including temperature at $2 \mathrm{~m}\left(T_{2}\right)$, relative humidity at $2 \mathrm{~m}\left(\mathrm{RH}_{2}\right)$ and wind speed at $10 \mathrm{~m}\left(\mathrm{WS}_{10}\right) \cdot{ }^{\mathrm{b}}$ Sites indicates the observation meteorological sites used in this study, including NJ in Nanjing, HF in Hefei, HZ in Hangzhou and SH in Shanghai. ${ }^{c}$ Mean represents the average value. ${ }^{d}$ CORR indicates the correlation coefficients, with statistical significance at the $95 \%$ confidence level. ${ }^{\text {e }}$ OBS represents the observation data. ${ }^{\mathrm{f}}$ SIM indicates the simulation results from WRF/Chem.

\subsection{Model evaluation for WRF/Chem}

Table 3 shows the statistical comparisons between meteorological observations and the model results from both January and July simulations in the ADDAH case. Mean values, MB, RMSE and CORR are all quantified for $2 \mathrm{~m}$ temperature $\left(T_{2}\right)$, $2 \mathrm{~m}$ relative humidity $\left(\mathrm{RH}_{2}\right)$ and $10 \mathrm{~m}$ wind speed $\left(\mathrm{WS}_{10}\right)$ at four grids where $\mathrm{NJ}, \mathrm{HF}, \mathrm{HZ}$ and $\mathrm{SH}$ are located. As shown in Table 3, the correlation coefficients between observations and simulations (CORR) are over 0.9 in January and about 0.8 in July for $T_{2}$, higher than 0.7 for $\mathrm{RH}_{2}$ at most sites in both months, and close to 0.7 for $\mathrm{WS}_{10}$ in January. So WRF/Chem simulates the urban meteorological conditions over the YRD region quite well. With respect to $T_{2}$, the modeling results are slightly overvalued at all sites, which might be attributed to the uncertainty caused by urban canopy and surface parameters (Kusaka and Kimura, 2004; Chen et al., 2011; Liao et al., 2015). But the level of overestimation is acceptable, because the MB values of $T_{2}$ are only $1.1-1.7^{\circ} \mathrm{C}$ in January and $0.7-2.0^{\circ} \mathrm{C}$ in July, with the RMSE of $T_{2} 1.6-$ $2.2^{\circ} \mathrm{C}$. The lowest value $0.7^{\circ} \mathrm{C}$ for $\mathrm{MB}$ and the highest value 0.94 for CORR illustrate the best $T_{2}$ estimation at SH. For $\mathrm{RH}_{2}$, compared with the observations, the simulation results are underestimated at all sites. Though the worst simulation of $\mathrm{RH}_{2}$ occurs at $\mathrm{HF}$, the results are reasonable at the other three sites. We find that the land-use data set cannot describe waters around $\mathrm{HF}$ well. In view of the fact that $\mathrm{HF}$ is not in the central area of the YRD region, the deviation at HF cannot introduce crucial uncertainty into our main conclusion. With regards to $\mathrm{WS}_{10}$, the modeling values from the ADDAH case are slightly overestimated at NJ, HF and HZ, whereas they are underestimated at $\mathrm{SH}$. The $\mathrm{MB}$ for $\mathrm{WS}_{10}$ is generally less than $0.5 \mathrm{~m} \mathrm{~s}^{-1}$, and the RMSE is less than $1.3 \mathrm{~m} \mathrm{~s}^{-1}$. These over- or under-estimates are attributable to near-surface wind speed being influenced by local underlying surface characteristics more than other meteorological parameters. Further improvement of urban canopy parameters might improve the simulations (Zhang et al., 2010; Liao et al., 2015).

Figure 5 presents time series comparisons between the observation data of $\mathrm{O}_{3}$ and $\mathrm{PM}_{10}$ at $\mathrm{CCM}$ and their modeling results from the ADDAH simulation case. Obviously, WRF/Chem with gridded AH fluxes can capture the diurnal variations and magnitude of these pollutants. For $\mathrm{O}_{3}$, the correlation coefficient between observations and simulations (CORR) is 0.60 in January and 0.71 in July (statistically significant at the $95 \%$ confident level). The value of $\mathrm{MB}$ is $-0.8 \mathrm{ppb}$ in January and $7.0 \mathrm{ppb}$ in July, which can be explained by stronger solar radiation reaching the urban surface in July, causing positive biases in $T_{2}$ and thereby producing more $\mathrm{O}_{3}$ within the PBL (Zhang et al., 2010; Liao et al., 2015). With regards to $\mathrm{PM}_{10}$, the model prediction underestimates the concentration, with MB being $-19.9 \mu \mathrm{g} \mathrm{m}^{-3}$ in January and $-10.8 \mu \mathrm{g} \mathrm{m}^{-3}$ in July, respectively. This underestimate can be partially ascribed to positive biases of $T_{2}$, which induce an increase in PBL height and cause $\mathrm{PM}_{10}$ dilution within the PBL (Liao et al., 2015). Furthermore, uncertainties in emissions may also cause these biases.

Liao et al. (2014) also simulated the same time periods in the YRD region by running WRF/Chem with a fixed AH flux in SLUCM. They found that the default SLUCM scheme tends to underestimate $2 \mathrm{~m}$ temperature in January but over- 
(a) January

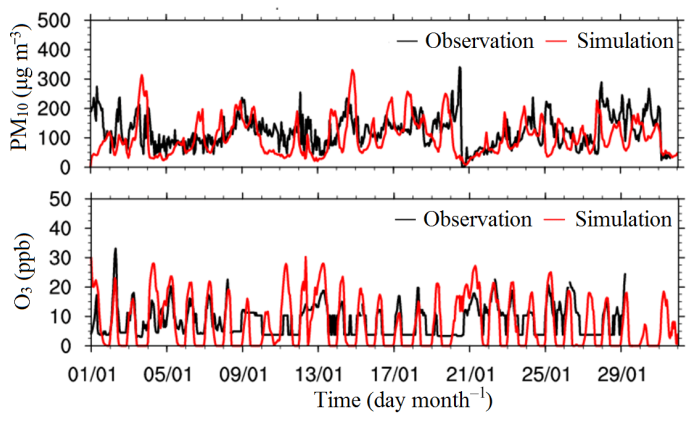

(b) July
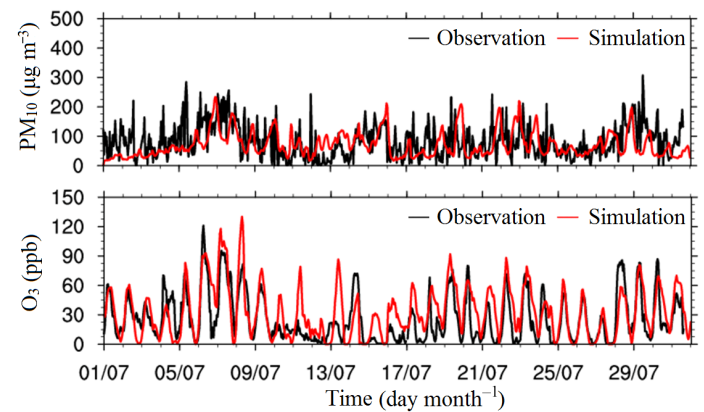

Figure 5. Hourly variations of $\mathrm{PM}_{10}\left(\mu \mathrm{g} \mathrm{m}^{-3}\right)$ and $\mathrm{O}_{3}(\mathrm{ppb})$ from the observation data and the ADDAH simulation results at the CCM monitoring site in Nanjing for January (a) and July (b).

estimate it in July, and overestimate the wind speed in both months. As a result, their chemical predictions are not so perfect either, with the CORR of $0.44-0.52$ for $\mathrm{O}_{3}$ and 0.19 0.33 for $\mathrm{PM}_{10}$. Compared with their results, our simulations accounting for the temporal and spatial distribution of $\mathrm{AH}$ improve the accuracy of the model results, and well predict the urban climate and air quality.

Generally, the WRF/Chem with gridded AH fluxes has a relatively good capability in simulating urban climate and air quality over the YRD region in this study. Though the biases are still found, the difference between the modeling results from NONAH and ADDAH can still quantify the impacts of anthropogenic heat on meteorology and pollution, because all other conditions are the same in both simulations.

\subsection{Impacts of AH on meteorological conditions}

\subsubsection{Horizontal meteorology changes}

Figure 6 presents the monthly averaged differences of the main meteorological factors between ADDAH and NONAH (ADDAH-NONAH) over modeling Domain 3 (D03). Differences that are non-significant under the $95 \%$ confidence level using a Student's $t$ test have been masked out. Obviously, the emissions of anthropogenic heat increase the sensible heat fluxes from the urban canopy layer over the YRD region. As shown in Fig. 6a and b, the spatial patterns of sensible heat changes in both January and July are similar to the spatial distribution of AH fluxes (Fig. 4d). High values of variation $\left(>10 \mathrm{~W} \mathrm{~m}^{-2}\right)$ generally occur around megacities with a positive magnitude. For instance, in Shanghai, due to the maximum $\mathrm{AH}$ fluxes in the city center, the biggest increase in sensible heat flux for January can be $82 \mathrm{~W} \mathrm{~m}^{-2}$, and the value is $75 \mathrm{~W} \mathrm{~m}^{-2}$ in July. In other cities, such as Hangzhou, Changzhou and Nantong, high values over $20 \mathrm{~W} \mathrm{~m}^{-2}$ can be found in both months as well. In order to better understand the different behavior during the daytime and at night, the monthly averaged diurnal variations of these modeled meteorological factors over the urban area of Shanghai in January and July are also calculated. As il- lustrated in Fig. 7, the addition of $\mathrm{AH}$ fluxes leads to an obvious increase in sensible heat flux (SHF) from 07:00 to 21:00 UTC, with the daily mean increase of $22 \mathrm{~W} \mathrm{~m}^{-2}$ for January and $20.5 \mathrm{~W} \mathrm{~m}^{-2}$ for July. The increases are insignificant at night because the AH fluxes are small during this time. On account of AH and its diurnal variation only being added to the sensible heat item, there are no significant differences between the ADDAH and NONAH simulations for ground heat flux (GRDFLX) and latent heat flux (LH). It is worth mentioning that many $\mathrm{AH}$ emission processes are related to water vapor releasing, and thereby latent heat fluxes might be affected by the human activities that release AH.

By adding more surface sensible heat into the atmosphere, the AH flux changes can influence the $2 \mathrm{~m}$ air temperature $\left(T_{2}\right)$ as well. The patterns of the monthly averaged $T_{2}$ changes (Fig. 6c and d) are similar to those of SHF (Fig. 6a and b). For city centers like Shanghai, Hangzhou and Nanjing, adding $\mathrm{AH}$ can lead to an increase in $T_{2}$ of over $1{ }^{\circ} \mathrm{C}$ in January and over $0.5^{\circ} \mathrm{C}$ in July, generating an enhanced urban heat island. The maximum $T_{2}$ changes usually occur in the city center of Shanghai, with the typical values of $1.6^{\circ} \mathrm{C}$ in January and $1.4^{\circ} \mathrm{C}$ in July. These findings are comparable to the values estimated in megacities all over the world (Fan and Sailor, 2005; Ferguson and Woodbury, 2007; Chen et al., 2009; Zhu et al., 2010; Menberg et al., 2013; Wu and Yang, 2013; Bohnenstengel et al., 2014; Feng et al., 2014; Yu et al., 2014). Moreover, the mean increase in $T_{2}$ at night in January $\left(1.2^{\circ} \mathrm{C}\right)$ is larger than that in the daytime $\left(1.0^{\circ} \mathrm{C}\right)$, whereas the increase during the daytime and nighttime is always equal to $0.6^{\circ} \mathrm{C}$ in July, suggesting that $\mathrm{AH}$ can help to form a weakened diurnal $T_{2}$ variation in winter.

The vertical air movement in the PBL can be enhanced by the warming up of surface air temperature, which might increase the height of the PBL (PBLH). Consequently, the enhanced AH fluxes increase the PBLH by more than $50 \mathrm{~m}$ in January and by more than $70 \mathrm{~m}$ in July over the YRD urban areas, with the maximum changes $(140 \mathrm{~m}$ for January and $160 \mathrm{~m}$ for July) occurring in Shanghai (shown in Fig. 6e and f). In summer, the weather is more unstable and the vertical 

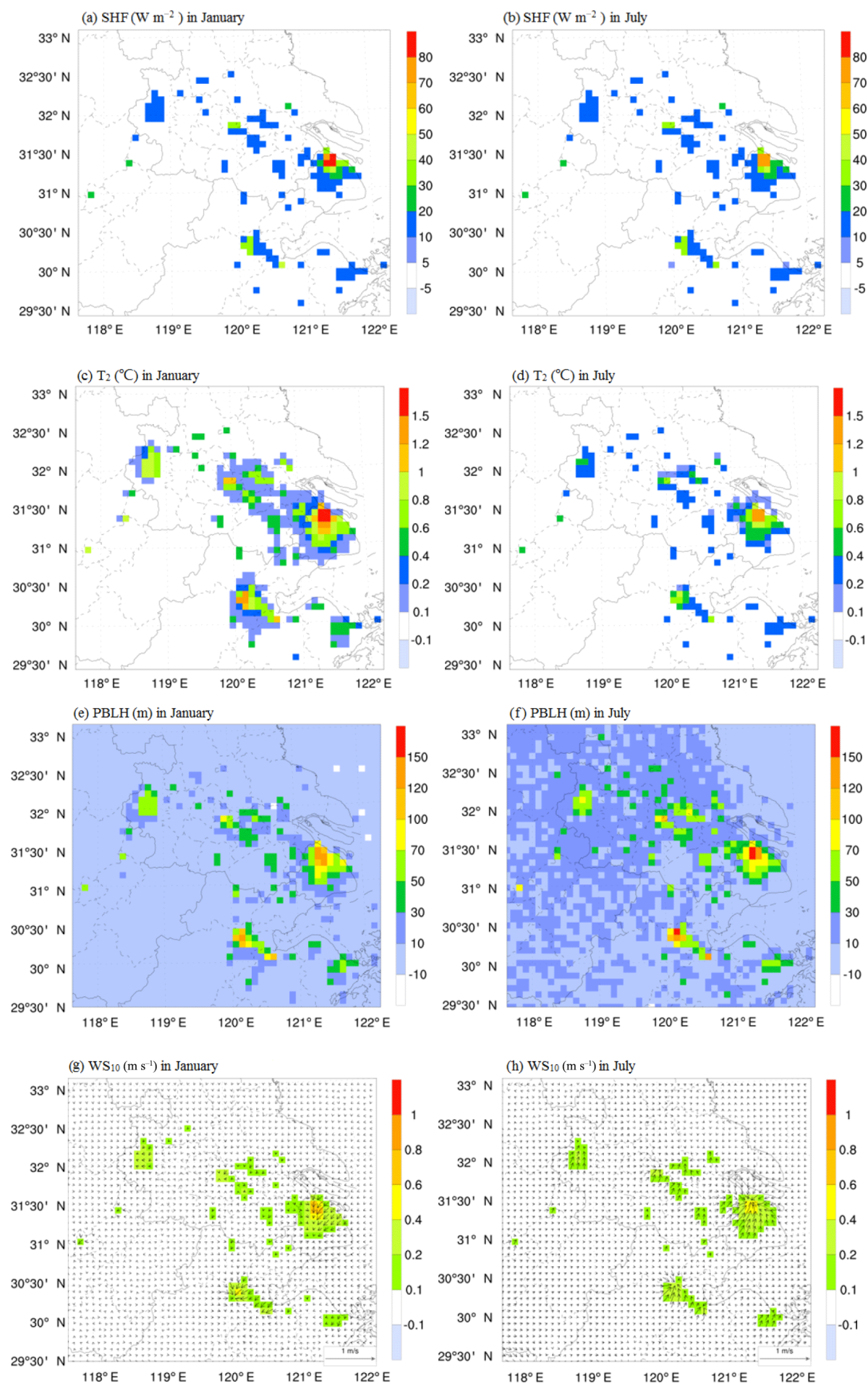

Figure 6. The spatial distributions of monthly averaged differences for sensible heat flux (SHF), air temperature at $2 \mathrm{~m}$ ( $\left.T_{2}\right)$, the height of the planetary boundary layer $(\mathrm{PBLH})$, and wind speed $\left(\mathrm{WS}_{10}\right)$ at $10 \mathrm{~m}$ between ADDAH and NONAH (ADDAH-NONAH). Panels (a), (c), (e) and (g) show changes in January. Panels (b), (d), (f) and (h) illustrate variations in July. The arrows in panels (g) and (h) are the differences of wind fields. Differences that are non-significant under the $95 \%$ confidence level (Student's $t$ test) are masked out. 

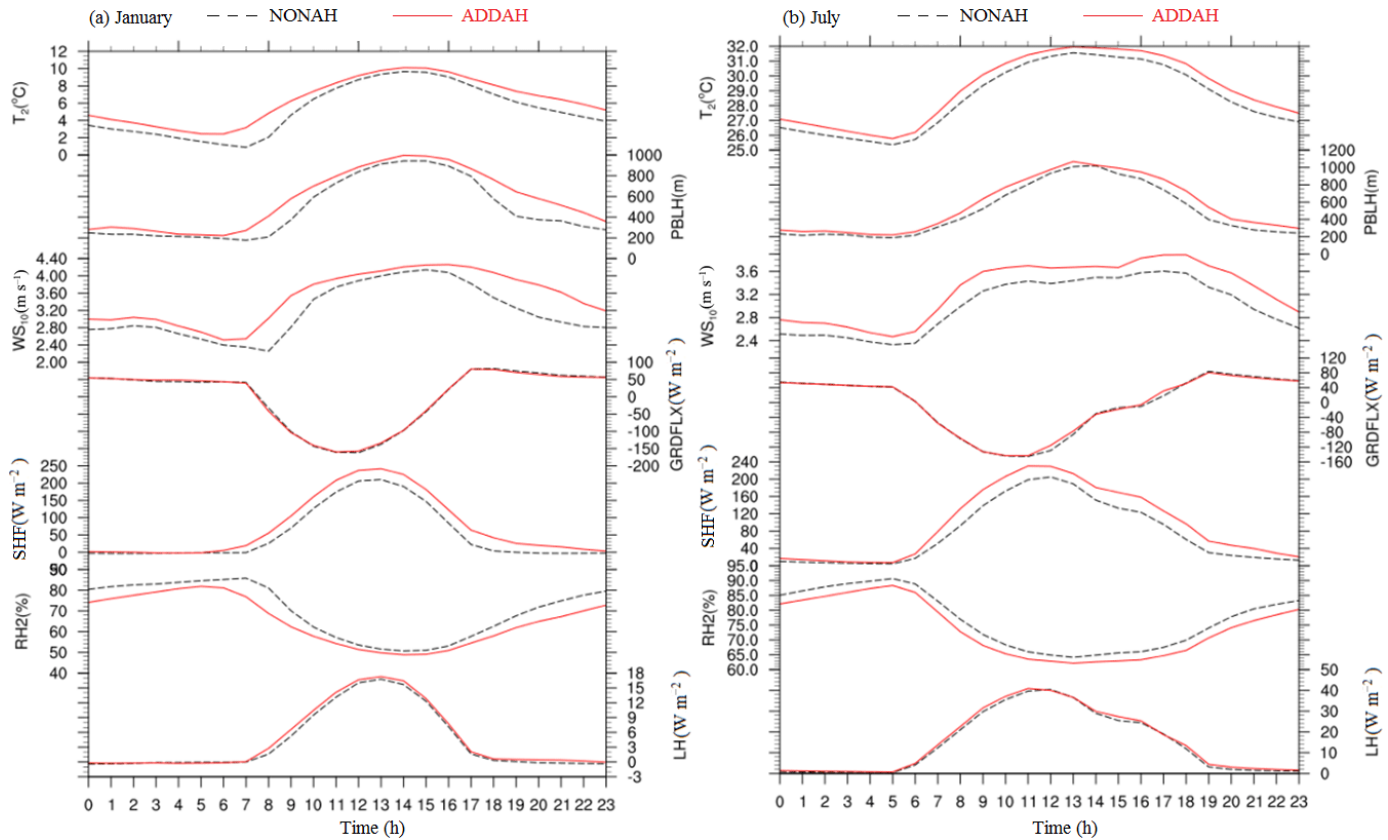

Figure 7. The monthly averaged diurnal variations of modeled meteorological factors in January (a) and July (b) over the urban area of Shanghai. NONAH and ADDAH represent the simulation cases with and without AH fluxes, respectively. LH means latent heat. SHF indicates sensible heat flux. GRDFLX represents heat flux from ground level. $T_{2}, \mathrm{RH}_{2}, \mathrm{WS}_{10}$, and PBLH indicate $2 \mathrm{~m}$ air temperature $\left({ }^{\circ} \mathrm{C}\right)$, $2 \mathrm{~m}$ relative humidity $(\%), 10 \mathrm{~m}$ wind speed $\left(\mathrm{m} \mathrm{s}^{-1}\right)$ and the height of the planetary boundary layer $(\mathrm{m})$, respectively.

convection is easy to form. So the adding of AH induces a greater increase in PBLH in July. For both months, as shown in Fig. 7, the daytime relative increase in PBLH (10-15\%) is smaller than that at night (23-33\%), which can be attributed to the facts that the absolute PBLH values are lower and the air temperature increases more during the nighttime.

Figure $6 \mathrm{~g}$ and $\mathrm{h}$ show the changes in wind components over the YRD region, and demonstrate that $\mathrm{AH}$ can enhance the $10 \mathrm{~m}$ wind speed $\left(\mathrm{WS}_{10}\right)$ in the urban areas. The maximum increase is located in Shanghai, with the increments of $0.7 \mathrm{~m} \mathrm{~s}^{-1}(19 \%)$ in January and $0.5 \mathrm{~m} \mathrm{~s}^{-1}(17 \%)$ in July. In other cities like Hangzhou and Nanjing, the added value is only about $0.3 \mathrm{~m} \mathrm{~s}^{-1}$. Over the YRD region, an increase in $\mathrm{WS}_{10}$ is more obvious in January (Fig. $6 \mathrm{~g}$ ) than in July (Fig. 6h), and is slightly higher at night than in the daytime (Fig. 7). As mentioned in previous studies, the above increase in wind speed can be ascribed to the strengthened urbanbreeze circulation caused by the enhanced AH fluxes (Chen et al., 2009; Ryu et al., 2013; Yu et al., 2014), which can be further clarified by the surface stronger convergence wind patterns occurring around the megacities shown in Fig. $6 \mathrm{~g}$ and $\mathrm{h}$. The simulated divergence at the surface near cities decreases by $0.07-0.23 \mathrm{~s}^{-1}$ in January and by $0.08-0.31 \mathrm{~s}^{-1}$ in July (not shown), also providing further evidence that the convergence is enhanced in these areas.

The strengthened urban-breeze circulation caused by adding $\mathrm{AH}$ can also enhance the vertical movement of the atmosphere. As shown in Fig. 8a, the simulated vertical ve- locity above the megacities on the $850 \mathrm{hPa}$ layer increases by about $2 \mathrm{~cm} \mathrm{~s}^{-1}$ in July, suggesting that the convection movements that can transport moisture and pollutants from the surface to the upper layer are strengthened in the urban areas. Thus, the spatial and vertical distributions of moisture are modified. Figure $8 \mathrm{c}$ and d illustrate the spatial plots for monthly averaged differences of $2 \mathrm{~m}$ relative humidity $\left(\mathrm{RH}_{2}\right)$ caused by adding AH (ADDAH-NONAH). The negative centers over the cities (the AH centers) can be seen in both January ( -2 to $-8 \%$ ) and July ( -2 to $-6 \%$ ), meaning the air near the surface became dryer. More moisture transported into the mid-troposphere (the vertical profile is discussed in Fig. 9g and $\mathrm{h}$ in detail) might enhance rainfall inside urban areas as well. As shown in Fig. 8b, the increase in rainfall in July can be 72.4, 84.6 and $63.2 \mathrm{~mm}$ in Shanghai, Hangzhou and Ningbo, respectively. However, because of the negligible accumulative precipitation in winter, the increment in rainfall over the YRD region in January can be ignored (not shown).

\subsubsection{Vertical meteorology changes}

To better understand how $\mathrm{AH}$ changes the vertical and spatial distribution of meteorology in the YRD region, we present changes (ADDAH - NONAH) in air temperature $(T)$, vertical wind velocity $(w)$, divergence (DIV) and water vapor mixing ratio (QVAPOR) along a cross section from $\left(28.9^{\circ} \mathrm{N}\right.$, $\left.118.1^{\circ} \mathrm{E}\right)$ to $\left(31.8^{\circ} \mathrm{N}, 122.6^{\circ} \mathrm{E}\right)$ as shown by the solid line 

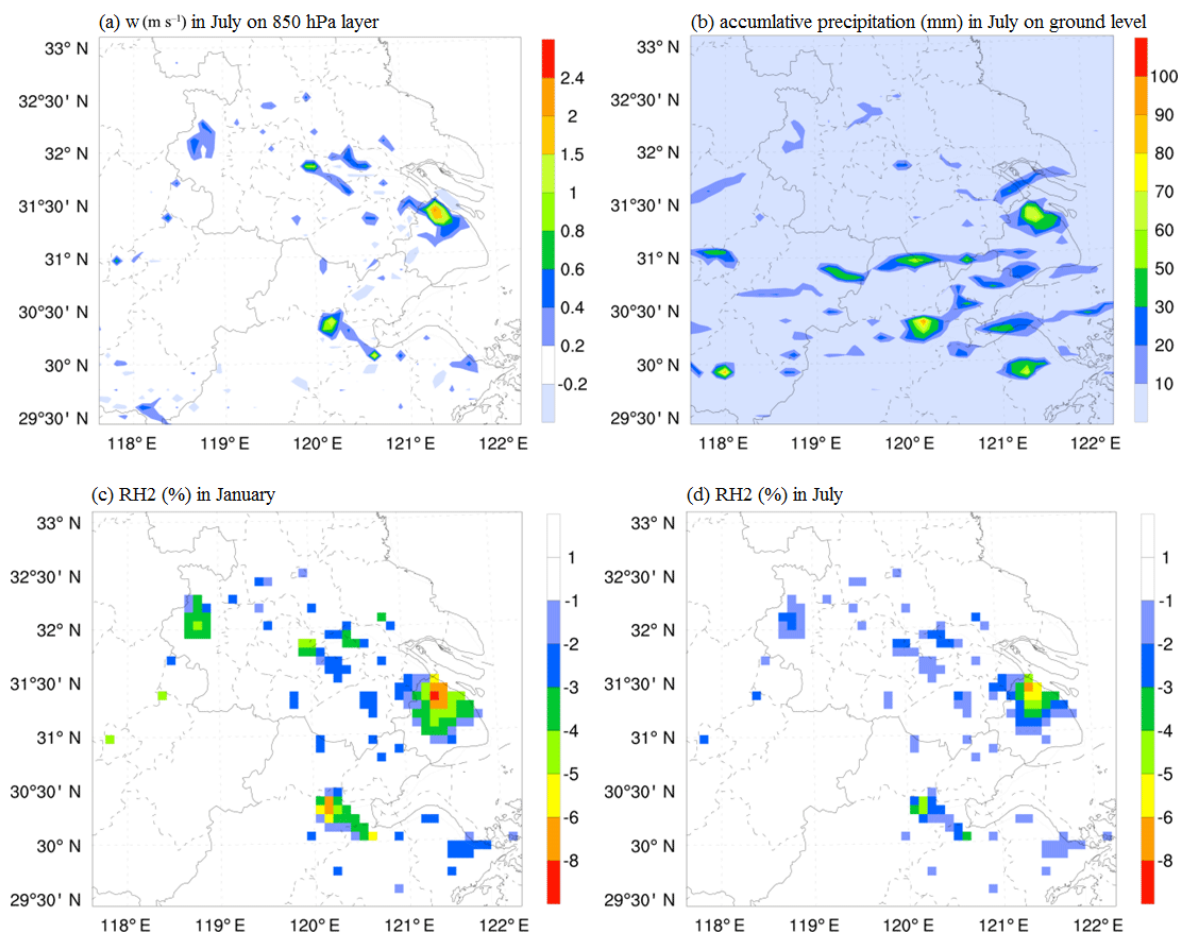

Figure 8. The spatial distributions of monthly averaged differences for vertical wind velocity on the $850 \mathrm{hPa}$ layer $(w)$, surface accumulative precipitation and $2 \mathrm{~m}$ relative humidity $\left(\mathrm{RH}_{2}\right)$ between ADDAH and NONAH (ADDAH-NONAH). Differences that are non-significant under the $95 \%$ confidence level (Student's $t$ test) are masked out.

$\mathrm{AB}$ in Fig. 2b. The vertical cross sections for $T$ changes (Fig. 9a and b) illustrate that adding AH leads to a significant increase in air temperature near the surface around the cities (Shanghai and Hangzhou), while the changes are close to 0 in the rural areas and free troposphere. The monthly mean increment of $T$ over Shanghai and Hangzhou at ground level in January $\left(0.7^{\circ} \mathrm{C}\right)$ is bigger than that in July $\left(0.4^{\circ} \mathrm{C}\right)$, which can be attributed to the fact that the relative increase in heat is higher in January due to background heat fluxes being much lower in winter.

The warming of air temperature near the surface in cities, as well as the rise in PBLH in these areas (Fig. 6e and f), can generate an enhanced urban heat island. As shown in Fig. 9c and d, the vertical wind velocities above Shanghai and Hangzhou increase with added values of $0.3-0.7 \mathrm{~cm} \mathrm{~s}^{-1}$ in both months, whereas $w$ in the rural areas decreases by about $-0.3 \mathrm{~m} \mathrm{~s}^{-1}$ in January and $-0.5 \mathrm{~cm} \mathrm{~s}^{-1}$ in July, suggesting that there is enhanced upward movement in cities and enhanced downward movement in the countryside. We also analyze the divergence changes along the cross section including Shanghai and Hangzhou (Fig. 9e and f). It can be seen that adding AH decreases DIV from the surface to $750 \mathrm{~m}$ and increases DIV at higher levels, which means that there is a stronger convergence wind pattern in the lower PBL and a more divergent wind pattern in the higher PBL. This change implies that the atmosphere is more unstable, and intends to promote the development of deep convection in the troposphere. Consequently, impacted by the strengthened urban-breeze circulation, more moisture is transported from the surface to the upper levels (over $1 \mathrm{~km}$ ), with a $0.6 \mathrm{~g} \mathrm{~kg}^{-1}$ decrease in QVAPOR at the ground level and a $0.1 \mathrm{~g} \mathrm{~kg}^{-1}$ increase for the upper PBL in July as presented in Fig. $9 \mathrm{~g}$ and h. Furthermore, the abovementioned vertical changes in $w$, DIV and QVAPOR are only restricted to the air column over the AH emission centers (Shanghai and Hangzhou) in January, while the changes are distributed widely (the adding AH fluxes can impact wider areas) in July. This seasonal difference can be ascribed to the fact that the atmosphere is more stagnant in winter and more convective in summer.

\subsection{Impacts of AH on air pollutants}

\subsubsection{Changes in surface $\mathrm{PM}_{10}$ and $\mathrm{O}_{3}$}

Adding AH changes spatial and vertical meteorology conditions, and thereby undoubtedly affects the transportation and dispersion of air pollutants. Due to $\mathrm{PM}_{10}$ being the main pollutant in the YRD region (Wang et al., 2012; Xie et al., 2014; Liao et al., 2015), it is chosen as an indicator to show the changes in primary air pollutants in this study. Figure 10 illustrates the influence of $\mathrm{AH}$ on $\mathrm{PM}_{10}$ spatial distribution in typical months of winter and summer (differences that are non-significant at the $95 \%$ confidence level using a $t$ test are masked out). Results show that $\mathrm{PM}_{10}$ in the lowest modeling 

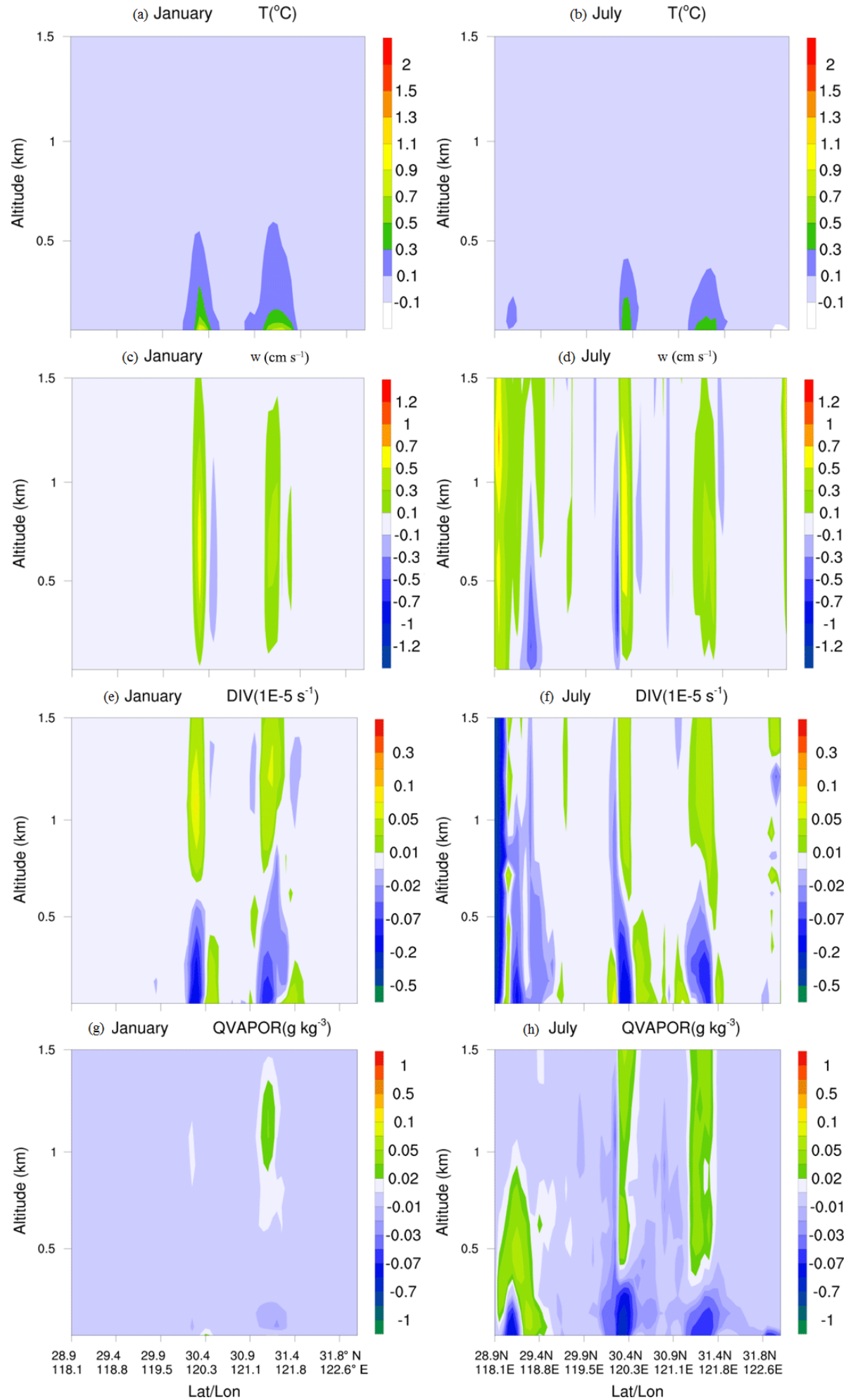

Figure 9. The vertical distribution of monthly averaged differences for air temperature $(T)$, vertical wind velocity ( $w$ ), divergence (DIV), and water vapor mixing ratio (QVAPOR) between ADDAH and NONAH (ADDAH-NONAH) from surface to $1.5 \mathrm{~km}$ altitude along line AB (shown in Fig. 2b). Panels (a), (c), (e) and (g) show changes in January. Panels (b), (d), (f) and (h) illustrate variations in July. Differences that are non-significant under the $95 \%$ confidence level (Student's $t$ test) are masked out. 

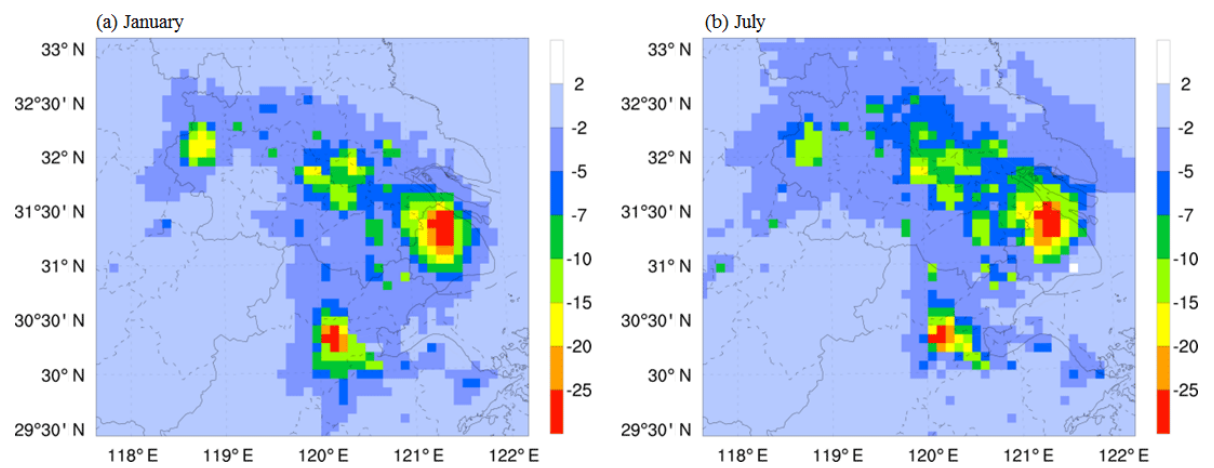

Figure 10. The spatial distributions of monthly averaged differences for $\mathrm{PM}_{10}$ between ADDAH and NONAH (ADDAH-NONAH). Differences that are non-significant under the $95 \%$ confidence level (Student's $t$ test) are masked out.

layer is reduced at all times around the cities, especially in Shanghai, Nanjing and Hangzhou. The maximum decrease usually appears in Shanghai, with the monthly mean reduction of $29.3 \mu \mathrm{g} \mathrm{m}^{-3}(24.5 \%)$ in January and $26.6 \mu \mathrm{g} \mathrm{m} \mathrm{m}^{-3}$ $(18.8 \%)$ in July. Compared with the distribution of AH emissions (Fig. 4) and meteorology changes (Fig. 6), the reduction in surface $\mathrm{PM}_{10}$ should be mainly related to the increase in PBLH, the rise in surface wind speed and the enhanced upward movement of air, because these modifications of meteorological conditions caused by adding $\mathrm{AH}$ over the urban areas can facilitate $\mathrm{PM}_{10}$ transport and dispersion within the urban boundary layer. Furthermore, on account of the precipitation around the cities increasing by $15-30 \%$, the wet scavenging can contribute to the reductions in the surface $\mathrm{PM}_{10}$ concentrations as well.

The spatial distribution of $\mathrm{O}_{3}$ concentration can also be influenced by the changes in meteorological conditions due to the adding of AH. It should be noted that the increase in wind speed might facilitate $\mathrm{O}_{3}$ transport, and the rise in PBLH can lead to $\mathrm{O}_{3}$ dilution within the planetary boundary layer. Thus, the surface $\mathrm{O}_{3}$ concentrations are seemingly reduced. However, unlike $\mathrm{PM}_{10}, \mathrm{O}_{3}$ is a secondary air pollutant formed by a series of complex chemical reactions involving oxides of nitrogen $\left(\mathrm{NO}_{x}=\mathrm{NO}+\mathrm{NO}_{2}\right)$ and volatile organic compounds (VOCs), so only considering the factors affecting $\mathrm{O}_{3}$ transport and dispersion is not sufficient. In fact, $\mathrm{O}_{3}$ changes are different from those of $\mathrm{PM}_{10}$. As illustrated in Fig. 11a and b, the increases in the surface $\mathrm{O}_{3}$ level can be seen in both January and July over the YRD region, with large increase centers occurring in megacities. In January (Fig. 11a), the maximum $\mathrm{O}_{3}$ difference appears in Shanghai, with the monthly mean increment of $2.5 \mathrm{ppb}(18 \%)$. In July (Fig. 11b), the highest $\mathrm{O}_{3}$ change occurs in Hangzhou, with the added value of $4 \mathrm{ppb}(15 \%)$. In the surrounding areas of these high-value centers, the increase in $\mathrm{O}_{3}$ associated with the introduction of $\mathrm{AH}$ can be over $0.5 \mathrm{ppb}$ in January and more than $1 \mathrm{ppb}$ in July. This change pattern and the magnitude are consistent with the findings reported in Beijing (Yu et al., 2014) and Seoul (Ryu et al., 2013).
Chemical direct and indirect effects should play a more important role in $\mathrm{O}_{3}$ changes than other physical influencing factors. On the one hand, the rise in air temperature (Fig. 6c and d) can directly accelerate $\mathrm{O}_{3}$ formation by increasing the chemical reaction rates, and thereby directly increase the $\mathrm{O}_{3}$ level at the surface. On the other hand, $\mathrm{O}_{3}$ changes are inextricably influenced by the changes in $\mathrm{NO}_{x}$ (indirect chemical effects). Similarly to other primary air pollutants (such as $\mathrm{PM}_{10}$ ), $\mathrm{NO}_{x}$ at ground level are reduced in both January and July due mainly to the increase in PBLH, surface wind speed and upward air movement caused by adding AH (Fig. 11c and d). It was reported that the $\mathrm{O}_{3}$ formation over the cities in the YRD region is sensitive to VOC (Xie et al., 2014), which means that a decrease in surface $\mathrm{NO}_{x}$ might lead to a slight increase in $\mathrm{O}_{3}$ during the daytime. At night, when the process of $\mathrm{NO}_{x}$ titration $\left(\mathrm{O}_{3}+\mathrm{NO} \rightarrow \mathrm{O}_{2}+\mathrm{NO}_{2}\right)$ supersedes the $\mathrm{O}_{3}$ sensitivity to be the governing factor of $\mathrm{O}_{3}$ chemistry, less $\mathrm{NO}_{x}$ can only consume less $\mathrm{O}_{3}$ as well. Consequently, the decrease in $\mathrm{NO}_{x}$ at the ground can result in the increase in $\mathrm{O}_{3}$. This indirect function might be clearly illustrated in the vertical distribution of $\mathrm{O}_{3}$ changes in Sect. 3.4.2.

\subsubsection{Vertical changes in $\mathrm{PM}_{10}$ and $\mathrm{O}_{3}$}

Figure 12 shows the vertical plots on cross-sectional line $A B$ (presented in Fig. 2b) for the changes in chemical species impacted by adding AH (ADDAH-NONAH). Differences that are non-significant at the $95 \%$ confidence level using a $t$ test have been masked out. For the primary air pollutants such as $\mathrm{PM}_{10}$ and $\mathrm{NO}_{x}$, the AH fluxes can decrease their concentrations near the surface. As shown in Fig. 12a and b, in the atmosphere below $300 \mathrm{~m}$ above Shanghai and Hangzhou, the concentrations of $\mathrm{PM}_{10}$ decrease by $2.3-16.2 \mu \mathrm{g} \mathrm{m}^{-3}$ in January and by $2.1-15.8 \mu \mathrm{g} \mathrm{m}^{-3}$ in July, respectively. Surface $\mathrm{NO}_{x}$ concentrations near Shanghai and Hangzhou can be reduced by over $15 \mathrm{ppb}$ in both months as well (Fig. 12c and d). Meanwhile, it was also found that there are increases in $\mathrm{PM}_{10}$ and $\mathrm{NO}_{x}$ concentrations at the upper levels over the cities. For instance, the added values of $\mathrm{PM}_{10}$ and $\mathrm{NO}_{x}$ can 

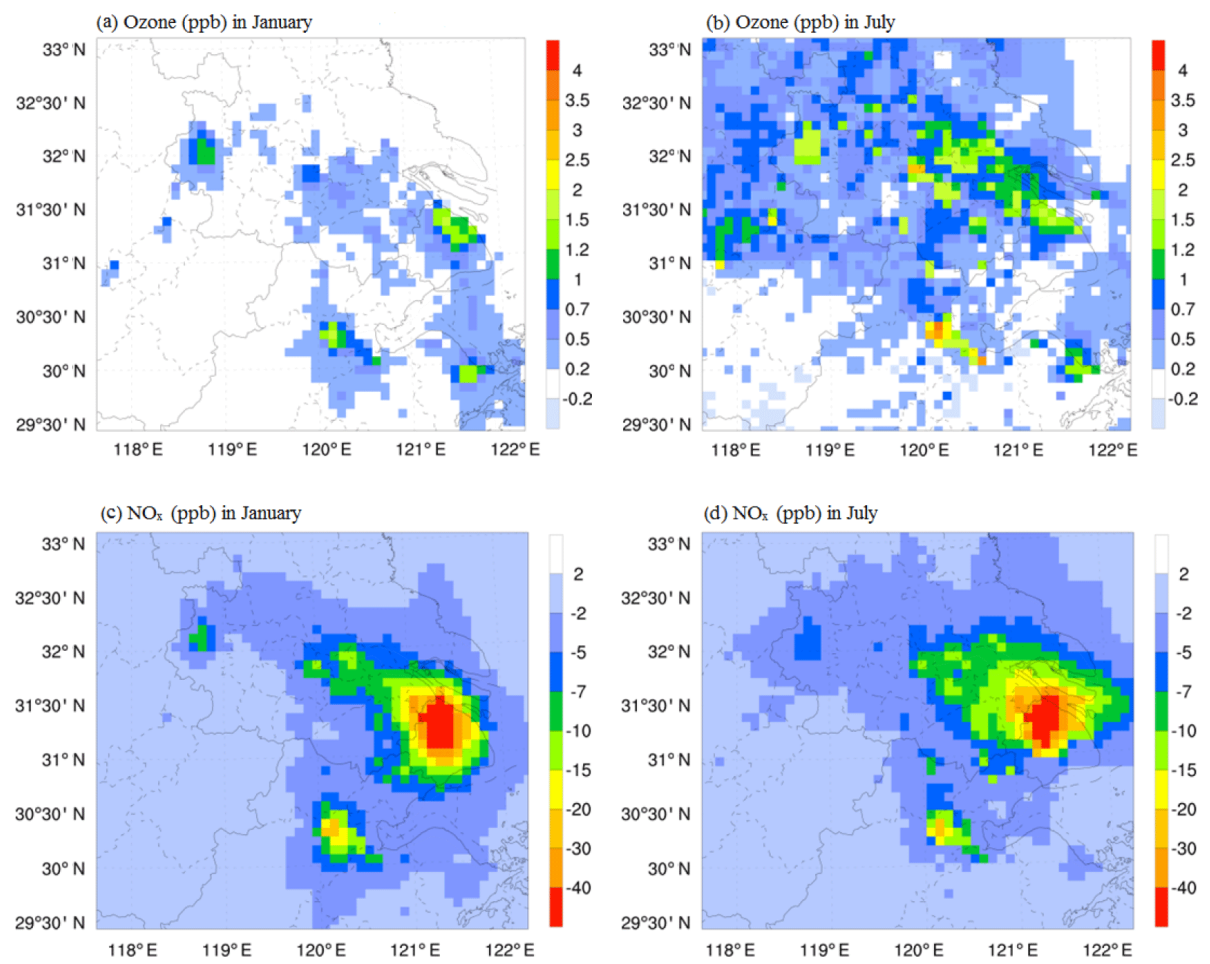

Figure 11. The spatial distributions of monthly averaged differences for $\mathrm{O}_{3}$ and its precursor $\mathrm{NO}_{x}$ between ADDAH and NONAH (ADDAHNONAH). Differences that are non-significant under the $95 \%$ confidence level (Student's $t$ test) are masked out.

be more than $3 \mu \mathrm{g} \mathrm{m}^{-3}$ and $3 \mathrm{ppb}$ at about $1 \mathrm{~km}$ above the surface in January, respectively. This vertical changing pattern for primary chemical species is quite similar to that for water vapor (Fig. $9 g$ and $h$ ), indicating that this is a reflection of the change in vertical transport patterns in the region due to AH (Yu et al., 2014). It should be noted that the maximum vertical changes in air pollutants in Hangzhou usually occur at about $1 \mathrm{~km}$ above the surface, whereas those in Shanghai generally appear at higher levels (>1 km), implying that more surface air pollutants in Shanghai might be transported into higher levels due to higher $\mathrm{AH}$ emissions in this biggest city in the YRD region. Furthermore, Fig. 13 shows the vertical profiles of the changes for $\mathrm{PM}_{10}, \mathrm{NO}_{x}$ and $\mathrm{O}_{3}$ caused by adding $\mathrm{AH}$ over Shanghai. In winter, the large increases in $\mathrm{PM}_{10}$ and $\mathrm{NO}_{x}$ appear at 500 to $1500 \mathrm{~m}$ above the surface. But the maximum increases usually occur at more than $1.5 \mathrm{~km}$ above the surface in summer. This phenomenon can be attributed to the fact that the atmosphere is more convective in summer than in winter.

In contrast to the primary air pollutants, $\mathrm{O}_{3}$ changes show increases near the surface and decreases at the upper levels over the urban areas. Figure 12e and $\mathrm{f}$ illustrates that the increases in $\mathrm{O}_{3}$ concentrations are limited within $400 \mathrm{~m}$ above the surface over the cities, with the high values of $2.6 \mathrm{ppb}$ in January and $4.2 \mathrm{ppb}$ in July. As mentioned in Sect. 3.4.1, this may be the result of both the increase in $\mathrm{O}_{3}$ production caused by a higher surface temperature and the decrease in
$\mathrm{O}_{3}$ depletion resulting from less surface NO. With respect to $\mathrm{O}_{3}$ concentrations from $400 \mathrm{~m}$ to $1.5 \mathrm{~km}$ above the surface, they generally decrease with the reduction in values of more than $1 \mathrm{ppb}$ in both January and July. Comparing Fig. 12e and $\mathrm{f}$ with Fig. 12c and d, we believe that the increases in $\mathrm{NO}_{x}$ concentrations at these upper levels can lead to the depletion of $\mathrm{O}_{3}$, because of the VOC-sensitive $\mathrm{O}_{3}$ chemistry in the daytime and $\mathrm{NO}_{x}$ titration at night in this region. In some previous studies on the $\mathrm{O}_{3}$ variations induced by urban land use, researchers also found that $\mathrm{O}_{3}$ chemical production is increased at the surface around big cities in summer (Liao et al., 2015; Zhu et al., 2015) and in winter (Liao et al., 2015). However, it was also found that the averaged daytime $\mathrm{O}_{3}$ in the upper PBL could significantly increase by $20-40 \mathrm{ppbv}$ because of strong urban heat island circulation in the summer of Shanghai (Zhu et al., 2015). This result implies that the vertical transport of $\mathrm{O}_{3}$ caused by urban land use should be stronger than that caused by $\mathrm{AH}$. Thus, more upward $\mathrm{O}_{3}$ can compensate for the depletion of $\mathrm{O}_{3}$ at upper levels.

\section{Conclusions}

Anthropogenic heat (AH) emissions from human activities caused by urbanization can affect the city environment. In this paper, we especially address its impacts on meteorological conditions and air pollution over the cities in the YRD region. Firstly, based on the energy consumption and the 

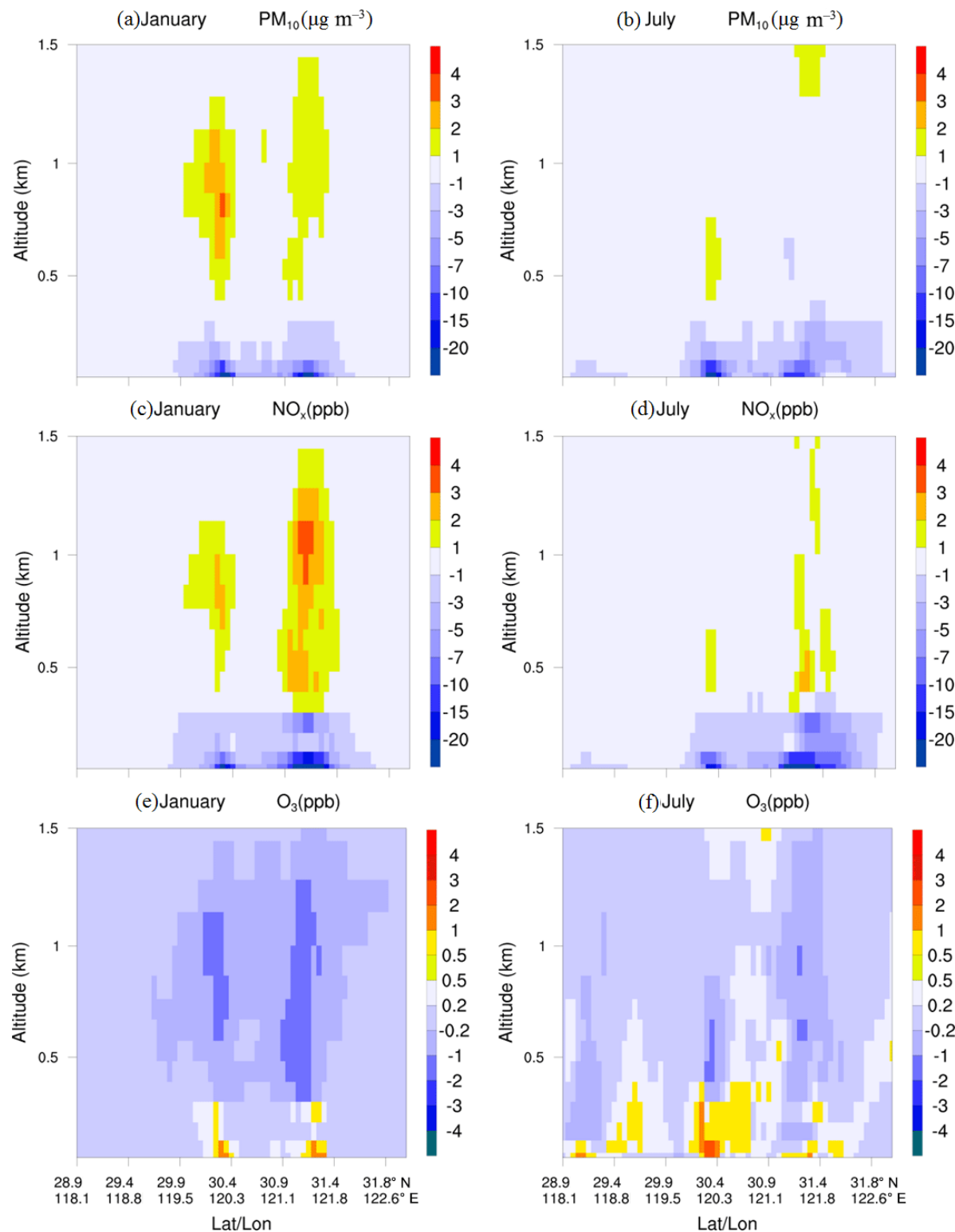

Figure 12. The vertical distribution of monthly averaged differences for $\mathrm{PM}_{10}, \mathrm{NO}_{x}$ and $\mathrm{O}_{3}$ between ADDAH and NONAH (ADDAHNONAH) from surface to $1.5 \mathrm{~km}$ altitude along line AB (shown in Fig. 2b). Panels (a), (c) and (e) show changes in January. Panels (b), (d) and (f) illustrate variations in July. Differences that are non-significant under the $95 \%$ confidence level (student $t$ test) are masked out.

gridded population data, we estimate the spatial distribution of AH fluxes by a top-down energy inventory method. Secondly, the gridded $\mathrm{AH}$ data with the seasonal and the diurnal variation are added to the sensible heat flux in the modified WRF/Chem. Finally, the WRF/Chem is applied to investigate the impacts of $\mathrm{AH}$. Two simulation cases are conducted. One incorporates the Single Layer Urban Canopy Model (SLUCM) with the gridded AH fluxes, while the other ignores the contribution of $\mathrm{AH}$.

The results show that the AH flux in the YRD region has increased continually since 1990 . During the period between 1990 and 2010, the annual-mean values of $\mathrm{AH}$ fluxes over
Shanghai, Jiangsu and Zhejiang have increased from 5.47 to $14.45 \mathrm{~W} \mathrm{~m}^{-2}, 0.68$ to $2.61 \mathrm{~W} \mathrm{~m}^{-2}$, and 0.33 to $1.63 \mathrm{~W} \mathrm{~m}^{-2}$, respectively. High AH fluxes generally occur in and around the cities. The typical values of AH in 2010 over the urban areas of Shanghai, Jiangsu and Zhejiang can reach 113.5, 50.2 and $39.3 \mathrm{~W} \mathrm{~m}^{-2}$, respectively.

The model results of WRF/Chem fit the observational meteorological conditions and air quality very well. Inclusion of the AH can enhance the urban heat island in the cities over the YRD region. The $2 \mathrm{~m}$ air temperature can increase by more than $1{ }^{\circ} \mathrm{C}$ in January and by over $0.5^{\circ} \mathrm{C}$ in July. The PBL heights can increase, with the maximum 


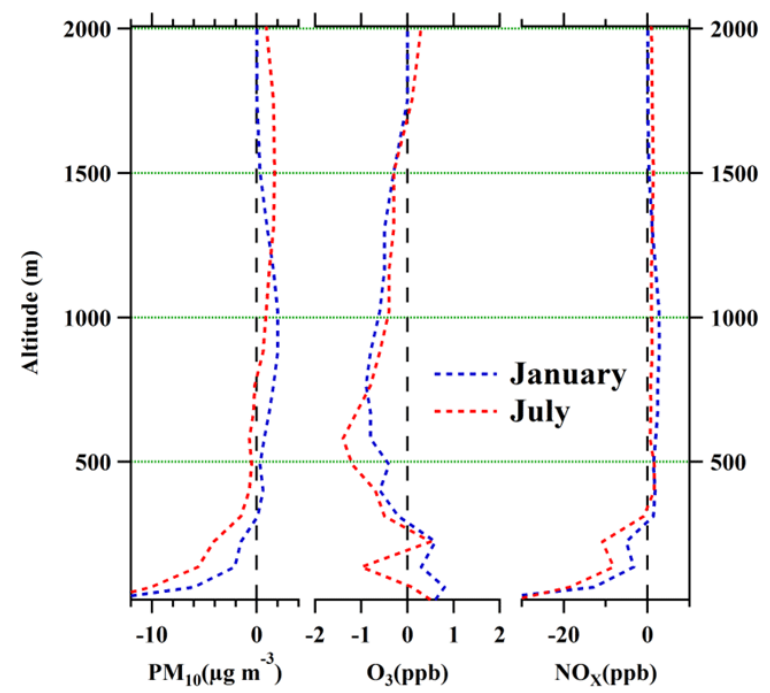

Figure 13. The vertical profiles of monthly averaged differences for $\mathrm{PM}_{10}, \mathrm{NO}_{x}$ and $\mathrm{O}_{3}$ between ADDAH and NONAH (ADDAHNONAH) over Shanghai.

changes of $140 \mathrm{~m}$ for January and $160 \mathrm{~m}$ for July in Shanghai. The strengthened urban-breeze circulation that resulted from adding the $\mathrm{AH}$ can enhance the $10 \mathrm{~m}$ wind speed and the vertical air movement as well. Thus, more moisture is transported from the surface to the upper levels, with a $0.6 \mathrm{~g} \mathrm{~kg}^{-1}$ decrease at the ground level and a $0.1 \mathrm{~g} \mathrm{~kg}^{-1}$ increase for the upper PBL in July, which might induce the accumulative precipitation to increase by $15-30 \%$ in Shanghai, Nanjing and Hangzhou.

Influenced by the modifications of meteorological conditions, the spatial and vertical distribution of air pollutants is modified. With respect to the primary air pollutants $\left(\mathrm{PM}_{10}\right.$ and $\mathrm{NO}_{x}$ ), their transport and dispersion in PBL can be facilitated by the increases in PBLH, surface wind speed and upward air movement, which causes the decreases in concentrations near the surface and the increases at the upper levels. Usually, $\mathrm{PM}_{10}$ can be reduced by $2-16 \mu \mathrm{g} \mathrm{m}^{-3}$ within $300 \mathrm{~m}$ above the surface of the cities, and added over $3 \mu \mathrm{g} \mathrm{m}^{-3}$ in the upper PBL. However, surface $\mathrm{O}_{3}$ concentrations increase in the urban areas, with maximum changes of $2.5 \mathrm{ppb}$ in January and $4 \mathrm{ppb}$ in July. Besides the rise in air temperature directly accelerating the surface $\mathrm{O}_{3}$ formation, the decrease in $\mathrm{NO}_{x}$ at the ground can also result in the increase in surface $\mathrm{O}_{3}$ due to the VOC-sensitive $\mathrm{O}_{3}$ chemistry in the daytime and $\mathrm{NO}_{x}$ titration at night in this region. Furthermore, $\mathrm{O}_{3}$ concentrations at higher levels are reduced by about $1 \mathrm{ppb}$ due mainly to the increase in $\mathrm{NO}$, and the impacts of $\mathrm{AH}$ are not only limited to the urban centers, but are also extended regionally.

Impact of anthropogenic heat emission on urban climate and air quality is undoubtedly an important and complex scientific issue. Our results show that the meteorology and air pollution predictions in and around large urban areas are highly sensitive to the anthropogenic heat inputs. Consequently, for further understanding of urban atmospheric environment issues, good information on land use, detailed urban structure of the cities and more studies of the anthropogenic heat release should be better considered.

\section{Data availability}

The population density data in 1990, 1995, 2000, 2005 and 2010 are available at http://sedac.ciesin.columbia.edu/gpw/ index.jsp. The observed meteorological data at four observation sites are accessible from http://weather.uwyo.edu/.

Acknowledgements. This work was supported by the National Natural Science Foundation of China (41475122, 91544230), the National Special Fund for Environmental Protection Research in the Public Interest (201409008), the Key Laboratory of South China Sea Meteorological Disaster Prevention and Mitigation of Hainan Province (SCSF201401), the National Science Foundation of Jiangsu Provence (BE2015151) and EU 7th Framework Marie Curie Actions IRSES project REQUA (PIRSES-GA-2013-612671). The authors would like to thank the anonymous reviewers for their constructive and valuable comments on this paper.

Edited by: A. Baklanov

\section{References}

Allen, L., Lindberg, F., and Grimmond, C. S. B.: Global to city scale urban anthropogenic heat flux: model and variability, Int. J. Climatol., 31, 1990-2005, doi:10.1002/joc.2210, 2011.

Block, A., Keuler, K., and Schaller, E.: Impacts of anthropogenic heat on regional climate patterns, Geophys. Res. Lett., 31, L12211, doi:10.1029/2004g1019852, 2004.

Bohnenstengel, S. I., Hamilton, I., Davies, M., and Belcher, S. E.: Impact of anthropogenic heat emissions on London's temperatures, Q. J. Roy. Meteor. Soc., 140, 687-698, doi:10.1002/qj.2144, 2014.

Chen, B., Shi, G. Y., Wang, B., Zhao, J. Q., and Tan, S. C.: Estimation of the anthropogenic heat release distribution in China from 1992 to 2009, Acta Meteorol. Sin., 26, 507-515, doi:10.1007/s13351-012-0409-y, 2012.

Chen, F. and Dudhia, J.: Coupling an advanced land surfacehydrology model with the Penn State-NCAR MM5 modeling system. Part I: Model implementation and sensitivity, Mon. Weather Rev., 129, 569-585, doi:10.1175/15200493(2001)129<0569:Caalsh>2.0.Co;2, 2001.

Chen, F., Kusaka, H., Bornstein, R., Ching, J., Grimmond, C. S. B., Grossman-Clarke, S., Loridan, T., Manning, K. W., Martilli, A., Miao, S. G., Sailor, D., Salamanca, F. P., Taha, H., Tewari, M., Wang, X. M., Wyszogrodzki, A. A., and Zhang, C. L.: The integrated WRF/urban modelling system: development, evaluation, and applications to urban environmental problems, Int. J. Climatol., 31, 273-288, doi:10.1002/joc.2158, 2011.

Chen, Y., Jiang, W. M., Zhang, N., He, X. F., and Zhou, R. W.: Numerical simulation of the anthropogenic heat effect on urban 
boundary layer structure, Theor. Appl. Climatol., 97, 123-134, doi:10.1007/s00704-008-0054-0, 2009.

Crutzen, P. J.: New Directions: The growing urban heat and pollution "island" effect - impact on chemistry and climate, Atmos. Environ., 38, 3539-3540, doi:10.1016/j.atmosenv.2004.03.032, 2004.

Fan, H. L. and Sailor, D. J.: Modeling the impacts of anthropogenic heating on the urban climate of Philadelphia: a comparison of implementations in two PBL schemes, Atmos. Environ., 39, 7384, doi:10.1016/j.atmosenv.2004.09.031, 2005.

Feng, J. M., Wang, J., and Yan, Z. W.: Impact of Anthropogenic Heat Release on Regional Climate in Three Vast Urban Agglomerations in China, Adv. Atmos. Sci., 31, 363-373, doi:10.1007/s00376-013-3041-z, 2014.

Ferguson, G. and Woodbury, A. D.: Urban heat island in the subsurface, Geophys. Res. Lett., 34, L23713, doi:10.1029/2007g1032324, 2007.

Flanner, M. G.: Integrating anthropogenic heat flux with global climate models, Geophys. Res. Lett., 36, L02801, doi:10.1029/2008g1036465, 2009.

Grimmond, C. S. B.: The Suburban Energy-Balance - Methodological Considerations And Results for a Midlatitude West-Coast City under Winter And Spring Conditions, Int. J. Climatol., 12, 481-497, doi:10.1002/joc.3370120506, 1992.

Guenther, A., Karl, T., Harley, P., Wiedinmyer, C., Palmer, P. I., and Geron, C.: Estimates of global terrestrial isoprene emissions using MEGAN (Model of Emissions of Gases and Aerosols from Nature), Atmos. Chem. Phys., 6, 3181-3210, doi:10.5194/acp-63181-2006, 2006.

Hamilton, I. G., Davies, M., Steadman, P., Stone, A., Ridley, I., and Evans, S.: The significance of the anthropogenic heat emissions of London's buildings: A comparison against captured shortwave solar radiation, Build. Environ., 44, 807-817, doi:10.1016/j.buildenv.2008.05.024, 2009.

He, X. F., Jiang, W. M., Chen, Y., and Liu, G.: Numerical simulation of the impacts of anthropogenic heat on the structure of the urban boundary layer, Chinese J. Geophys.-Ch., 50, 74-82, 2007.

Iamarino, M., Beevers, S., and Grimmond, C. S. B.: High-resolution (space, time) anthropogenic heat emissions: London 1970-2025, Int. J. Climatol., 32, 1754-1767, doi:10.1002/joc.2390, 2012.

Ichinose, T., Shimodozono, K., and Hanaki, K.: Impact of anthropogenic heat on urban climate in Tokyo, Atmos. Environ., 33, 3897-3909, doi:10.1016/S1352-2310(99)00132-6, 1999.

Janjic, Z. I.: The Step-Mountain Eta Coordinate Model - Further Developments Of the Convection, Viscous Sublayer, And Turbulence Closure Schemes, Mon. Weather Rev., 122, 927-945, doi:10.1175/1520-0493(1994)122<0927:Tsmecm>2.0.Co;2, 1994.

Kain, J. S.: The Kain-Fritsch convective parameterization: An update, J. Appl. Meteorol., 43, 170-181, doi:10.1175/15200450(2004)043<0170:Tkcpau>2.0.Co;2, 2004.

Kang, H. Q., Zhu, B., Zhu, T., Sun, J. L., and Ou, J. J.: Impact of Megacity Shanghai on the Urban Heat-Island Effects over the Downstream City Kunshan, Bound.-Lay. Meteorol., 152, 411426, doi:10.1007/s10546-014-9927-1, 2014.

Khan, S. M. and Simpson, R. W.: Effect of a heat island on the meteorology of a complex urban airshed, Bound.-Lay. Meteorol., 100, 487-506, doi:10.1023/A:1019284332306, 2001.
Kikegawa, Y., Genchi, Y., Yoshikado, H., and Kondo, H.: Development of a numerical simulation system toward comprehensive assessments of urban warming countermeasures including their impacts upon the urban buildings' energy-demands, Appl. Energ., 76, 449-466, doi:10.1016/S0306-2619(03)00009-6, 2003.

Kim, H. J. and Wang, B.: Sensitivity of the WRF Model Simulation of the East Asian Summer Monsoon in 1993 to Shortwave Radiation Schemes and Ozone Absorption, Asia-Pac. J. Atmos. Sci., 47, 167-180, doi:10.1007/s13143-011-0006-y, 2011.

Kusaka, H. and Kimura, F.: Coupling a single-layer urban canopy model with a simple atmospheric model: Impact on urban heat island simulation for an idealized case, J. Meteorol. Soc. Jpn., 82, 67-80, doi:10.2151/Jmsj.82.67, 2004.

Lee, S. H., Song, C. K., Baik, J. J., and Park, S. U.: Estimation of anthropogenic heat emission in the Gyeong-In region of Korea, Theor. Appl. Climatol., 96, 291-303, doi:10.1007/s00704-0080040-6, 2009.

Li, L., Chen, C. H., Fu, J. S., Huang, C., Streets, D. G., Huang, H. Y., Zhang, G. F., Wang, Y. J., Jang, C. J., Wang, H. L., Chen, Y. R., and Fu, J. M.: Air quality and emissions in the Yangtze River Delta, China, Atmos. Chem. Phys., 11, 16211639, doi:10.5194/acp-11-1621-2011, 2011.

Liao, J. B., Wang, T. J., Wang, X. M., Xie, M., Jiang, Z. Q., Huang, X. X., and Zhu, J. L.: Impacts of different urban canopy schemes in WRF/Chem on regional climate and air quality in Yangtze River Delta, China, Atmos. Res., 145, 226-243, doi:10.1016/j.atmosres.2014.04.005, 2014.

Liao, J. B., Wang, T. J., Jiang, Z. Q., Zhuang, B. L., Xie, M., Yin, C. Q., Wang, X. M., Zhu, J. L., Fu, Y., and Zhang, Y.: WRF/Chem modeling of the impacts of urban expansion on regional climate and air pollutants in Yangtze River Delta, China, Atmos. Environ., 106, 204-214, doi:10.1016/j.atmosenv.2015.01.059, 2015.

Lin, Y. L., Farley, R. D., and Orville, H. D.: Bulk Parameterization Of the Snow Field In a Cloud Model, J. Clim. Appl. Meteorol., 22, 1065-1092, doi:10.1175/15200450(1983)022<1065:Bpotsf>2.0.Co;2, 1983.

Liu, Q., Lam, K. S., Jiang, F., Wang, T. J., Xie, M., Zhuang, B. L., and Jiang, X. Y.: A numerical study of the impact of climate and emission changes on surface ozone over South China in autumn time in 2000-2050, Atmos. Environ., 76, 227-237, doi:10.1016/j.atmosenv.2013.01.030, 2013.

Lu, Y., Wang, Q. G., Zhai, Y. R., Song, Y. Y., Zhang, Y. Y., and Sun, P.: Anthropogenic heat emissions in the Yangtze River Delta region, China Environmental Science, 34, 295-301, 2014.

Menberg, K., Bayer, P., Zosseder, K., Rumohr, S., and Blum, P.: Subsurface urban heat islands in German cities, Sci. Total Environ., 442, 123-133, doi:10.1016/j.scitotenv.2012.10.043, 2013.

Mlawer, E. J., Taubman, S. J., Brown, P. D., Iacono, M. J., and Clough, S. A.: Radiative transfer for inhomogeneous atmospheres: RRTM, a validated correlated-k model for the longwave, J. Geophys. Res.-Atmos., 102, 16663-16682, doi:10.1029/97jd00237, 1997.

Offerle, B., Grimmond, C. S. B., and Fortuniak, K.: Heat storage and anthropogenic heat flux in relation to the energy balance of a central European city centre, Int. J. Climatol., 25, 1405-1419, doi:10.1002/joc.1198, 2005.

Oke, T. R.: The Urban Energy-Balance, Prog. Phys. Geog., 12, 471508, doi:10.1177/030913338801200401, 1988. 
Pigeon, G., Legain, D., Durand, P., and Masson, V.: Anthropogenic heat release in an old European agglomeration (Toulouse, France), Int. J. Climatol., 27, 1969-1981, doi:10.1002/joc.1530, 2007.

Quah, A. K. L. and Roth, M.: Diurnal and weekly variation of anthropogenic heat emissions in a tropical city, Singapore, Atmos. Environ., 46, 92-103, doi:10.1016/j.atmosenv.2011.10.015, 2012.

Ryu, Y. H., Baik, J. J., and Lee, S. H.: Effects of anthropogenic heat on ozone air quality in a megacity, Atmos. Environ., 80, 20-30, doi:10.1016/j.atmosenv.2013.07.053, 2013.

Sailor, D. J.: A review of methods for estimating anthropogenic heat and moisture emissions in the urban environment, Int. J. Climatol., 31, 189-199, doi:10.1002/joc.2106, 2011.

Sailor, D. J. and Lu, L.: A top-down methodology for developing diurnal and seasonal anthropogenic heating profiles for urban areas, Atmos. Environ., 38, 2737-2748, doi:10.1016/j.atmosenv.2004.01.034, 2004.

Streets, D. G., Yarber, K. F., Woo, J. H., and Carmichael, G. R.: Biomass burning in Asia: Annual and seasonal estimates and atmospheric emissions, Global Biogeochem. Cy., 17, 1099, doi:10.1029/2003gb002040, 2003.

Wang, T. J., Jiang, F., Deng, J. J., Shen, Y., Fu, Q. Y., Wang, Q., Fu, Y., Xu, J. H., and Zhang, D. N.: Urban air quality and regional haze weather forecast for Yangtze River Delta region, Atmos. Environ., 58, 70-83, doi:10.1016/j.atmosenv.2012.01.014, 2012.

Wang, X. M., Chen, F., Wu, Z. Y., Zhang, M. G., Tewari, M., Guenther, A., and Wiedinmyer, C.: Impacts of Weather Conditions Modified by Urban Expansion on Surface Ozone: Comparison between the Pearl River Delta and Yangtze River Delta Regions, Adv. Atmos. Sci., 26, 962-972, doi:10.1007/s00376-009-80012, 2009.

Wang, X. M., Sun, X. G., Tang, J. P., and Yang, X. Q.: Urbanizationinduced regional warming in Yangtze River Delta: potential role of anthropogenic heat release, Int. J. Climatol., 35, 4417-4430, doi:10.1002/joc.4296, 2015.

Wu, K. and Yang, X. Q.: Urbanization and heterogeneous surface warming in eastern China, Chinese Sci. Bull., 58, 1363-1373, doi:10.1007/s11434-012-5627-8, 2013.

Xie, M., Zhu, K. G., Wang, T. J., Yang, H. M., Zhuang, B. L., Li, S., Li, M. G., Zhu, X. S., and Ouyang, Y.: Application of photochemical indicators to evaluate ozone nonlinear chemistry and pollution control countermeasure in China, Atmos. Environ., 99, 466-473, doi:10.1016/j.atmosenv.2014.10.013, 2014.
Xie, M., Zhu, K. G., Wang, T. J., Feng, W., Zhu, X. S., Chen, F., Ouyang, Y., and Liu, Z. J.: Study on the distribution of anthropogenic heat flux over China, China Environmental Science, 35, 728-734, 2015.

Yang, W. M., Jiang, H., Yu, X. Y., and Cui, X. F.: Review of research on anthropogenic heat under climate change, Progress In Geography, 33, 1029-1038, 2014.

Yu, M., Carmichael, G. R., Zhu, T., and Cheng, Y. F.: Sensitivity of predicted pollutant levels to anthropogenic heat emissions in Beijing, Atmos. Environ., 89, 169-178, doi:10.1016/j.atmosenv.2014.01.034, 2014.

Zaveri, R. A. and Peters, L. K.: A new lumped structure photochemical mechanism for large-scale applications, J. Geophys. Res.Atmos., 104, 30387-30415, doi:10.1029/1999jd900876, 1999.

Zaveri, R. A., Easter, R. C., Fast, J. D., and Peters, L. K.: Model for Simulating Aerosol Interactions and Chemistry (MOSAIC), J. Geophys. Res.-Atmos., 113, D13204, doi:10.1029/2007jd008782, 2008.

Zhang, N., Gao, Z. Q., Wang, X. M., and Chen, Y.: Modeling the impact of urbanization on the local and regional climate in Yangtze River Delta, China, Theor. Appl. Climatol., 102, 331342, doi:10.1007/s00704-010-0263-1, 2010.

Zhang, Q., Streets, D. G., Carmichael, G. R., He, K. B., Huo, H., Kannari, A., Klimont, Z., Park, I. S., Reddy, S., Fu, J. S., Chen, D., Duan, L., Lei, Y., Wang, L. T., and Yao, Z. L.: Asian emissions in 2006 for the NASA INTEX-B mission, Atmos. Chem. Phys., 9, 5131-5153, doi:10.5194/acp-9-5131-2009, 2009.

Zhu, B., Kang, H. Q., Zhu, T., Su, J. F., Hou, X. W., and Gao, J. H.: Impact of Shanghai urban land surface forcing on downstream city ozone chemistry, J. Geophys. Res.-Atmos., 120, 4340-4351, doi:10.1002/2014JD022859, 2015.

Zhu, K., Blum, P., Ferguson, G., Balke, K. D., and Bayer, P.: The geothermal potential of urban heat islands, Environ. Res. Lett., 5, 044002, doi:10.1088/1748-9326/5/4/044002, 2010.

Zhuang, B. L., Li, S., Wang, T. J., Deng, J. J., Xie, M., Yin, C. Q., and Zhu, J. L.: Direct radiative forcing and climate effects of anthropogenic aerosols with different mixing states over China, Atmos. Environ., 79, 349-361, doi:10.1016/j.atmosenv.2013.07.004, 2013a.

Zhuang, B. L., Liu, Q., Wang, T. J., Yin, C. Q., Li, S., Xie, M., Jiang, F., and Mao, H. T.: Investigation on semi-direct and indirect climate effects of fossil fuel black carbon aerosol over China, Theor. Appl. Climatol., 114, 651-672, doi:10.1007/s00704-0130862-8, 2013b. 